\title{
Plasmodium transmission blocking activities of Vernonia amygdalina extracts and isolated compounds
}

Solomon M Abay ${ }^{1,2^{*}}$, Leonardo Lucantoni ${ }^{1,6}$, Nisha Dahiya ${ }^{1}$, Geme Dori ${ }^{1}$, Edson G Dembo ${ }^{1}$, Fulvio Esposito ${ }^{1}$, Guilio Lupidi ${ }^{1}$, Sonny Ogboi ${ }^{1}$, Robert K Ouédraogo ${ }^{1,3}$, Annamaria Sinisi ${ }^{4}$, Orazio Taglialatela-Scafati ${ }^{4}$, R Serge Yerbanga ${ }^{3}$, Massimo Bramucci ${ }^{1}$, Luana Quassinti ${ }^{1}$, Jean Bosco Ouédraogo ${ }^{3}$, George Christophides ${ }^{5}$ and Annette Habluetzel ${ }^{1}$

\begin{abstract}
Background: Medicinal plants are a validated source for discovery of new leads and standardized herbal medicines. The aim of this study was to assess the activity of Vernonia amygdalina leaf extracts and isolated compounds against gametocytes and sporogonic stages of Plasmodium berghei and to validate the findings on field isolates of Plasmodium falciparum.
\end{abstract}

Methods: Aqueous (Ver- $\left.\mathrm{H}_{2} \mathrm{O}\right)$ and ethanolic (Ver-EtOH) leaf extracts were tested in vivo for activity against sexual and asexual blood stage $P$. berghei parasites. In vivo transmission blocking effects of Ver-EtOH and Ver- $\mathrm{H}_{2} \mathrm{O}$ were estimated by assessing P. berghei oocyst prevalence and density in Anopheles stephensi mosquitoes. Activity targeting early sporogonic stages (ESS), namely gametes, zygotes and ookinetes was assessed in vitro using $P$. berghei CTRP $P_{\mathrm{p}}$.GFP strain. Bioassay guided fractionation was performed to characterize $V$. amygdalina fractions and molecules for anti-ESS activity. Fractions active against ESS of the murine parasite were tested for ex vivo transmission blocking activity on $P$. falciparum field isolates. Cytotoxic effects of extracts and isolated compounds vernolide and vernodalol were evaluated on the human cell lines HCT116 and EA.hy926.

Results: Ver- $\mathrm{H}_{2} \mathrm{O}$ reduced the $P$. berghei macrogametocyte density in mice by about $50 \%$ and Ver-EtOH reduced $P$. berghei oocyst prevalence and density by 27 and 90\%, respectively, in An. stephensi mosquitoes. Ver-EtOH inhibited almost completely (>90\%) ESS development in vitro at $50 \mu \mathrm{g} / \mathrm{mL}$. At this concentration, four fractions obtained from the ethylacetate phase of the methanol extract displayed inhibitory activity $>90 \%$ against ESS. Three tested fractions were also found active against field isolates of the human parasite $P$. falciparum, reducing oocyst prevalence in Anopheles coluzzii mosquitoes to one-half and oocyst density to one-fourth of controls. The molecules and fractions displayed considerable cytotoxicity on the two tested cell-lines.

Conclusions: Vernonia amygdalina leaves contain molecules affecting multiple stages of Plasmodium, evidencing its potential for drug discovery. Chemical modification of the identified hit molecules, in particular vernodalol, could generate a library of druggable sesquiterpene lactones. The development of a multistage phytomedicine designed as preventive treatment to complement existing malaria control tools appears a challenging but feasible goal.

Keywords: Malaria transmission blocking, Gametocytes, Sporogonic stages, Plasmodium, Phytomedicine, Vernonia amygdalina, Sesquiterpene lactone

\footnotetext{
*Correspondence: solomonabay@gmail.com

1 School of Pharmacy, University of Camerino, Piazza dei Costanti,

62032 Camerino, MC, Italy

Full list of author information is available at the end of the article
} 


\section{Background}

Despite intensive efforts to control malaria, the disease continues to be one of the greatest health problems faced by sub-Saharan African countries [1]. About 207 million clinical cases of malaria occurred in 2012 according to WHO estimates, maintaining its deplorable ranking as one of the top killer diseases [2]. Among the drugs currently used for malaria case management, artemisinin based combination therapy (ACT) [3] and primaquine [4] have impact on malaria transmission, by reducing the infectiousness of individuals to mosquitoes [5]. Clinical evidence indicate that activity of artemisinin derivatives is restricted to developing gametocytes, whereas primaquine is able to hit also the circulating mature gametocytes [6]. On the basis of the drugs' respective activity profiles, the World Health Organization (WHO) recommends the addition of a single dose of primaquine to the ACT course for the management of uncomplicated Plasmodium falciparum malaria in areas threatened by artemisinin resistance and/or in pre-elimination phase [7]. However, a viable alternative to primaquine is urgently needed, considering that this compound can provoke haemolytic anaemia in patients with glucose6-phosphate dehydrogenase deficiency [8]. Among the various available approaches, the exploration of empirically effective and chemically characterized anti-malarial plants represents a valid strategy for the discovery of new druggable compounds active against gametocytes and/ or sporogonic stages for the development of multi-stage combination medicines.

The connection between medicinal plants and successful anti-malarial drug discovery dates back to 1820, time of quinine isolation from Cinchona bark [9] and continues to the current time, as witnessed by the development of various potent forms of ACT based on semisynthetic derivatives of artemisinin, a highly oxygenated sesquiterpene isolated as active principle of Artemisia annua [10]. The multistage activity of artemisinin derivatives on asexual blood stages and early gametocytes [11], has encouraged researchers to explore molecules of plant origin seeking not only activity on parasite stages developing in the vertebrate host, but also transmission blocking effects against the sporogonic stages developing in the mosquito vector. Recently, Lucantoni et al. demonstrated the in vivo transmission blocking property of azadirachtin A enriched formulation $\left(\mathrm{NeemAzal}^{\circledR}\right)$ on Plasmodium berghei sporogonic development in Anopheles stephensi mosquitoes [12]. When administered to mice at an azadirachtin A dose of $50 \mathrm{mg} / \mathrm{kg}$, the commercial Azadirachta indica seed extract [13] was found to completely block parasite development in the vector. Azadirachtin A has been shown to inhibit the formation of flagellate microgametes from microgametocytes with an $\mathrm{IC}_{50}$ of $3.5 \mu \mathrm{M}$ [14], suggesting that microgametogenesis is a main target process of NeemAzal ${ }^{\circledR}$ transmission blocking action. The transmission blocking activity of this azadirachtin A rich neem product was recently confirmed in the human parasite P. falciparum by studies conducted in Burkina Faso on field isolates: gametocytaemic blood supplemented with 70 ppm NeemAzal ${ }^{\circledR}$ and membrane fed to Anopheles coluzzii mosquitoes completely inhibited oocyst development and therefore infection in mosquitoes [15].

In many African countries, where malaria is endemic and in particular in rural areas where access to modern health care facilities is often hindered, traditional practices still play an important role. People give preference to the use of herbal remedies for several reasons including: easier access, lower cost, lack of awareness about modern drugs and belief that the use of traditional medicine is more safe and effective [16]. Currently, standardized anti-malarial phytomedicines are officially commercialized in various malaria endemic countries over the world, namely China, Ghana, India, Mali and Burkina Faso. Among few such products for which clinical research has been conducted, encouraging results were obtained with Qing hao (Artemisia annua, Democratic Republic of Congo trials), Totaquina (Cinchona spp., Multicounty trials) and Phyto-laria (Cryptolepis sanguinolenta, Ghana trial) showing a parasite clearance at days 5-7 after treatment of $70-100,92-100$ and $100 \%$, respectively. These findings support their use as complementary tools to the conventional anti-malarial interventions or as alternative treatments in the absence of anti-malarial drugs [17].

In sub-Saharan countries, including Ethiopia, leaves of Vernonia amygdalina (Asteraceae) are used for the treatment and prevention of malaria [18-21]. The anti-plasmodial activity of this small shrub has been confirmed by several in vitro [22-26] and in vivo studies [27-30]. In a 4-day suppression test involving the administration of extracts immediately after mouse infection with $P$. berghei, a parasitaemia suppression of $67 \%$ was demonstrated for ethanolic and methanolic extracts at doses of $500 \mathrm{mg} / \mathrm{kg}$ (s.c.) and $1,000 \mathrm{mg} / \mathrm{kg}$ (p.o.), respectively [27, 31], while an aqueous extract given to mice at $125 \mathrm{mg} /$ $\mathrm{kg}$ (p.o.) caused a 63\% reduction of parasitaemia [28]. Employing the Rane test that involves the administration of extracts 3 days post-infection for the evaluation of curative efficacy, $200 \mathrm{mg} / \mathrm{kg}$ (i.p.) of aqueous [30] and $500 \mathrm{mg} / \mathrm{kg}$ (s.c.) of ethanolic extract [27] suppressed parasitaemia by 74 and $71 \%$, respectively. Interestingly, in a clinical trial examining the efficacy of an infusion of fresh $V$. amygdalina leaves in patients with uncomplicated falciparum malaria, an adequate clinical response was reported in $67 \%$ of the cases. However, complete parasite clearance occurred in only $32 \%$ of patients with 
adequate clinical response, and among these, recrudescence occurred in $71 \%$ [31].

Several secondary metabolites have been isolated and characterized from $V$. amygdalina leaves, such as sesquiterpene lactones [32-35], steroidal saponins (vernoniosides) [36], and flavonoids (luteolin and its glycosides) [37]. The class of sesquiterpene lactones is probably the most peculiar of this plant and it includes the highly oxygenated derivatives vernolide [32], vernodalol [32], vernodalinol [33], epivernodalol [34], vernodalin and vernomygdalin [35] and vernolepin [38]. Vernolide and vernodalin exhibited $\mathrm{IC}_{50}$ of 1.87 and $0.52 \mu \mathrm{g} / \mathrm{mL}$, respectively, against $P$. falciparum blood stages in vitro [39]. In another study, $\mathrm{IC}_{50}$ values of 8.4, 4.0, 4.2 and $11.4 \mu \mathrm{g} / \mathrm{mL}$ were obtained for vernolide, vernodalin, vernodalol and hydroxyvernolide, respectively [40].

On the basis of the above-illustrated broad knowledge available on $V$. amygdalina as an anti-malarial plantfrom its evidenced appreciable clinical efficacy to the partially characterized activity profile of some secondary metabolite-this plant has been selected as a valid candidate for investigation on potential inhibitors of Plasmodium transmission stages.

The present study was aimed at characterizing the plant extracts for stage specific effects on gametocytes and sporogonic stages and at identifying the responsible compounds through a bio-guided fractionation approach, then validating them on P. falciparum field isolates.

\section{Methods}

\section{Plant material}

\section{Source}

Vernonia amygdalina (Asteraceae) leaves were collected in the area of Karat town, located in Konso district, i.e., $600 \mathrm{~km}$ south of Addis Ababa, Ethiopia, after the rainy season (October 2011). A leaf specimen was used for taxonomic identification, and authenticated by Mr. Melaku Wondafrash, a plant taxonomist. A voucher specimen was deposited (Solomon-0l) at the National Herbarium, Addis Ababa University, Ethiopia.

\section{Preparation of extracts and fractions, and isolation of compounds}

Vernonia amygdalina leaves were air-dried at room temperature in the shade and ground using a blender. Ground material (50 g) was macerated in ethanol (EtOH) for $24 \mathrm{~h}$ and filtered with filter paper (Whatman ${ }^{\circledR}$ no. 1 ). Ethanol was removed using a rotary evaporator at $40^{\circ} \mathrm{C}$ under reduced pressure. The extract was further concentrated by freeze drying and stored at $-20^{\circ} \mathrm{C}$ until use. To prepare the aqueous extract $\left(\right.$ Ver- $\left.\mathrm{H}_{2} \mathrm{O}\right), 50 \mathrm{~g}$ of ground $V$. amygdalina leaves were macerated in distilled water for $24 \mathrm{~h}$, then filtered and freeze dried. The percent yields of the aqueous and ethanol extractions were 14 and $8 \%$, respectively.

To identify secondary metabolites responsible for transmission blocking activity, bio-guided fractionation was employed on a methanol $(\mathrm{MeOH})$ extract of $V$. amygdalina leaves. Briefly, $450 \mathrm{~g}$ of leaf powder was macerated in $1 \mathrm{~L}$ of $\mathrm{MeOH}$ for $24 \mathrm{~h}$ for three times. The extract was then filtered and concentrated with rotary evaporator to obtain a dried $\mathrm{MeOH}$ extract (34.5 g, yield $7.6 \%)$. A portion of this extract $(27.9 \mathrm{~g})$ was then partitioned, first between water and ethyl acetate (EtOAc), and then between water and butanol $(\mathrm{BuOH})$, to get the following phases: EtOAc (14.3 g), $\mathrm{BuOH}(4.9 \mathrm{~g})$ and $\mathrm{H}_{2} \mathrm{O}(7.9 \mathrm{~g})$. The EtOAc phase was selected for bioassay-guided fractionation. It was subjected to medium pressure liquid chromatography (MPLC) over a column packed with silica gel (230-400 mesh) and eluted with the following solvent gradient of increasing polarity: $n$-hexane, to $n$-hexane:EtOAc (9:1), $n$-hexane:EtOAc (4:1), $n$-hexane:EtOAc (7:3), $n$-hexane:EtOAc (3:2), $n$-hexane:EtOAc $(1: 1), \quad n$-hexane:EtOAc $\quad(7: 11)$, n-hexane:EtOAc (1:4), EtOAc, EtOAc:MeOH (1:1) and finally $\mathrm{MeOH}$. A total of 40 eluates of $250 \mathrm{~mL}$ each were collected and combined on the basis of thin layer chromatography behaviour, to get 14 fractions which were then tested for anti-plasmodial activities in vitro.

The active fractions (fr. 11-14) were further purified by high performance liquid chromatography (HPLC) on a Knauer apparatus equipped with a refractive index detector and LUNA $(5 \mu, 250 \times 4 \mathrm{~mm}$ Phenomenex) SI60 or Kinetex $(2.6 \mu, 100 \times 4.60 \mathrm{~mm}$ Phenomenex $) \mathrm{C} 18 \mathrm{col}-$ umns. Fractions 11 and 12 were separated by HPLC (eluent $n$-hexane/EtOAc 75:25, flow $0.8 \mathrm{~mL} / \mathrm{min}$ ) to get pure vernolide (125.3 mg). Fractions 13 and 14 were separated by HPLC (eluent $n$-hexane/EtOAc $1: 1$, flow $0.8 \mathrm{~mL} / \mathrm{min}$ ) to obtain pure vernodalol $(108.5 \mathrm{mg})$. The chemical structures of vernolide and vernodalol are reported in Fig. 1. These compounds were identified by comparison of their spectral data, particularly NMR $\left({ }^{1} \mathrm{H}\right.$ NMR at $500 \mathrm{MHz}$ and ${ }^{13} \mathrm{C}$ NMR at $125 \mathrm{MHz}$ measured on Varian INOVA

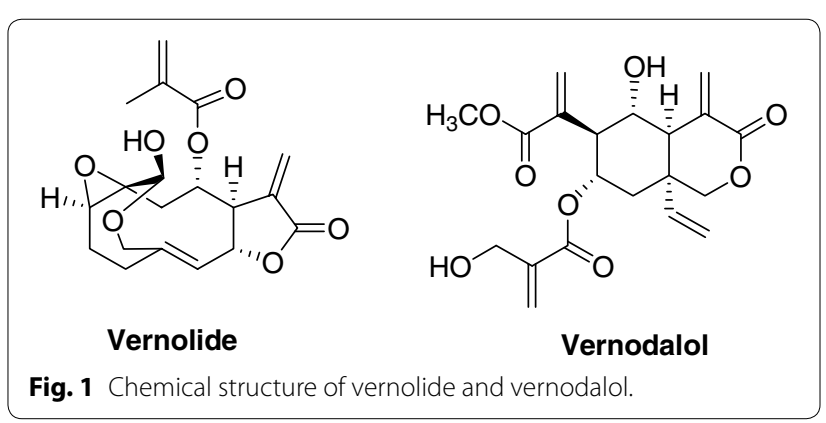


spectrometers) with those published in the literature [41, $42]$.

\section{Plasmodium species}

The following three strains of the murine malaria parasite $P$. berghei were employed in transmission blocking experiments: (1) P. berghei ANKA strain (chloroquine and pyrimethamine-sensitive) $[43,44]$ for the assessment of extracts' activity against sexual and asexual blood stages in vivo; (2) P. berghei GFPcon (chloroquine-sensitive and pyrimethamine-resistant) [43, 44] expressing a green fluorescent protein (GFP) at all life cycle stages, for the evaluation of extracts' transmission blocking activity in vivo; (3) P. berghei CTRP .GFP strain (chloroquinesensitive and pyrimethamine-resistant), expressing GFP in zygotes and ookinetes [45, 46], for the assessment of extracts/fractions/molecules' activity against the development of early sporogonic stages (ESS) in vitro. The $P$. berghei CTRP $_{\mathrm{P}}$.GFP strain was kindly provided by Prof. R.E. Sinden from Imperial College of London, UK.

Plasmodium falciparum parasites isolated from individuals living in a hyperendemic area of Burkina Faso were employed to confirm transmission blocking effects on the human parasite species. The details of ethical approval are presented below in the ethical clearance section.

\section{Mosquitoes}

For the in vivo transmission blocking studies with $P$. berghei, An. stephensi mosquitoes were used as experimental vectors. The mosquito colony was maintained at a temperature of $30^{\circ} \mathrm{C}\left( \pm 2^{\circ} \mathrm{C}\right), 12 \mathrm{~h}$ light $/ 12 \mathrm{~h}$ dark cycle and $75-85 \%$ relative humidity in the insectary of the University of Camerino, Italy. Experiments were conducted with four to 5 days-old female mosquitoes that had been transferred to a $19^{\circ} \mathrm{C}$ chamber (temperature required for the development of $P$. berghei in the vector) $24 \mathrm{~h}$ prior to administration of infectious blood-meals.

For the ex vivo transmission blocking assay performed with P. falciparum field isolates, 4-5 days old An. coluzzii mosquitoes (previously classified as Anopheles gambiae form " $M$ ") [47] were used. The colony, routinely reared in the insectary of the "Institut de Recherche en Sciences de la Santé", Bobo-Dioulasso, Burkina Faso has been originally established from field collected mosquitoes in 2008.

\section{Mice}

Eight to ten weeks old BALB/c mice, weighing between 18 and $25 \mathrm{~g}$ were used in this study. The mice were reared in the animal house of the University of Camerino at $24^{\circ} \mathrm{C}, 14 \mathrm{~h}$ light $/ 10 \mathrm{~h}$ dark cycle and $70 \%$ relative humidity, fed on standard laboratory mice pellets (Mucedola s.r.l., Milano, Italy) and provided with tap water ad-libitum. Experimental animal rearing and handling were in compliance with the Italian Legislative Decree on the "use and protection of laboratory animals" (D. Lgs. 116 of 10/27/92) and in full adherence with the European Directive 2010/63/UE. The mice were narcotized with a 1:1 mixture of xylazine and acepromazine at 13\% inoculate in $100 \mu \mathrm{L}$ phosphate buffered saline (PBS) i.p. before any mosquito bites procedures. At the end of experiments, carbon dioxide inhalation was the method of humane euthanasia used for mice.

\section{Murine malaria model}

The rodent in vivo malaria model consisting of $P$. berghei ANKA strain parasites, BALB/c mice as vertebrate hosts and An. stephensi mosquitoes as vectors, is routinely employed in drug discovery research for the assessment of in vivo transmission blocking and parasite suppression efficacy $[12,48-50]$ and has been validated by Coleman and colleagues [51]. This model was employed here to evaluate the in vivo transmission blocking and gametocytocidal activity of $V$. amygdalina extracts.

\section{Experimental procedures \\ Assessment of impact on parasite development in the vertebrate host and determination of gametocytocidal activity}

Ethanolic (Ver-EtOH) and aqueous $\left(\right.$ Ver- $\left.\mathrm{H}_{2} \mathrm{O}\right)$ extracts of $\mathrm{V}$. amygdalina leaves at a dose of $500 \mathrm{mg} / \mathrm{kg}$ of mouse body weight were orally administered to experimental animals allocated to the treatment groups. This dosage corresponds approximately to the amount of the plant material taken up by malaria patients, according to the traditional medicine recipe [18]. For administration, Ver-EtOH was dissolved in distilled water containing $7.5 \%$ Tween 80 and $10 \%$ ethanol, while Ver- $\mathrm{H}_{2} \mathrm{O}$ was dissolved in distilled water only. Animals in the control group received a similar volume of the solvent used to dissolve the extracts. The daily dose of each extract was divided in two equal parts, and gavages were performed twice a day at an interval of $12 \mathrm{~h}$, in a of $200 \mu \mathrm{L} /$ mouse each. In each treatment and control group, six mice were used. Treatments were administered for a total of 9 days, starting 2 days before infection of the experimental mice through the bites of 12-14 Anopheles females harbouring sporozoites in their salivary glands [52]. On day 7 post-infection, thin blood smears were prepared and stained with 7.5\% Giemsa solution (Merck, Germany) for $50 \mathrm{~min}$. Smears were examined under a microscope with oil immersion objective $(100 \times)$ to assess parasitaemia (all stages) and gametocyte densities. Plasmodium berghei infected red blood cells (RBCs) were counted out of 100 total RBCs on three microscopic fields to determine parasitaemia. For low parasitaemias ( $<1 \%)$, up to 4,000 total 
erythrocytes have been counted. To estimate gametocytaemia, microgametocytes and macrogametocytes were counted in at least 16 fields against 2,500 infected RBCs.

\section{Assessment of transmission blocking activity in vivo}

The in vivo transmission blocking effect of $V$. amygdalina was estimated by determining oocyst prevalence and density in mosquitoes fed on extract-treated gametocytaemic mice [12]. Briefly, mice were inoculated with $10^{7}$ P. berghei GFPcon-infected red blood cells (RBCs) through the intraperitoneal (i.p.) route. On day 3 post-infection, animals allocated to the treatment groups were treated i.p. with 500 and $100 \mathrm{mg} /$ $\mathrm{kg}$ (maximum tolerable dose) of $\mathrm{Ver}-\mathrm{H}_{2} \mathrm{O}$ and Ver-EtOH, respectively, while control animals received $200 \mu \mathrm{L}$ of the solvents used to dissolve the extracts. On day 4 post-infection, the treatment was repeated $1 \mathrm{~h}$ before the exposure of the mice to mosquitoes (day 4 gametocytes yield consistently high mosquito infections in this model). Mice were anaesthetized and kept on top of mosquito cages containing 150-200 An. stephensi females for $1 \mathrm{~h}$. Unfed females were removed the following day. On day 10/11 after the blood meal, 17-34 mosquitoes from each cage were dissected. Oocyst prevalence and density were assessed by counting the number of green fluorescent oocysts on mosquito mid-guts under a fluorescence microscope (ZEISS Axio Observer Z1, FITC filter 9) (Fig. 2). Oocyst density was determined by calculating the geometric mean of the number of oocysts recorded on oocyst positive mosquitoes [53].

Geometric mean $=\operatorname{antilog}\left(\left[\sum_{i=1}^{n} \log x\right] / n\right)$, where $\mathrm{n}=$ Number of oocyst positive mosquitoes, $x=$ Oocyst number per mosquito

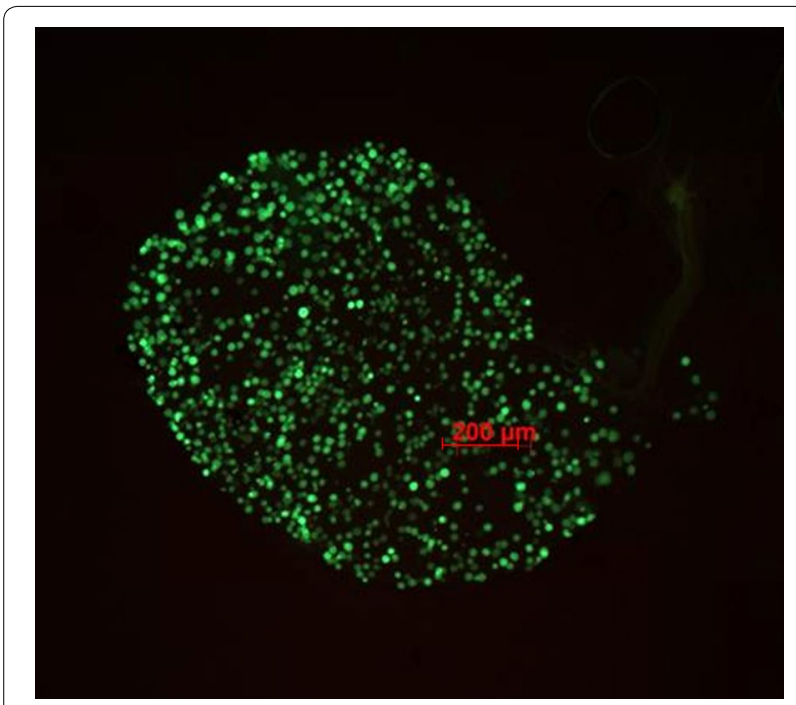

Fig. 2 Plasmodium berghei GFPcon oocysts on mosquito mid-gut, 10 days after infection.
The percent reduction of oocyst density in treatment groups was calculated as follows:

\section{Percent reduction of oocyst density}

$=\left(1-\frac{\text { average oocyst density in treated group }}{\text { average oocyst density in control group }}\right) \times 100$

The experiment was conducted in triplicate, using for each treatment group three mice and for each mouse one cage of mosquitoes.

\section{Evaluation of effects on early sporogonic stages in vitro}

The impact of V. amygdalina on the development of ESS was evaluated according to the method described by Delves et al. [54] with slight modifications.

\section{Source of gametocytes}

To stimulate erythropoiesis, mice were treated with phenylhydrazine (120 mg/kg i.p.) 4 days before being infected with P. berghei CTRP ${ }_{\mathrm{p}}$.GFP through i.p. injection of $10^{7}$ infected RBCs. Gametocytaemia was checked 4 days post-infection by microscopic examination of thin blood films and the maturity of microgametocytes verified by testing their capacity to generate flagellate microgametes in an exflagellation assay. In brief, for each gametocytaemic mouse a drop of tail blood was diluted at a ratio of about 1:25 in exflagellation medium (RPMI 1640 containing $25 \mathrm{mM}$ HEPES, $25 \mathrm{mM}$ sodium bicarbonate, $50 \mathrm{mg} / \mathrm{L}$ hypoxanthine, $100 \mu \mathrm{M}$ xanthurenic acid, $\mathrm{pH}$ 7.6-8). Then, $8 \mu \mathrm{L}$ of the diluted blood sample were placed centrally on a hand-made chamber consisting of a microscope slide as a base, two cover slips placed on it laterally as spacers, and a third one put on the top to close the chamber. To avoid drying out of the $8 \mu \mathrm{L}$ blood droplet, the chamber was sealed with a mixture of Vaseline and Tween 80 (approximately 1:2 ratio). After $20 \mathrm{~min}$ incubation at $19^{\circ} \mathrm{C}$, slides were examined for exflagellation under the microscope (400× magnification) (Fig. 3). Mice with abundant exflagellation centres (more than 3 per 1,000 red blood cells) were selected for the ookinete development assay.

\section{Ookinete development assay (ODA)}

This assay allows the assessment of inhibition of the early sporogonic development in the vector, including male and female gametogenesis, zygote formation and ookinete maturation. To simulate the physicochemical conditions of the mosquito midgut environment in vitro, $180 \mu \mathrm{L}$ of ookinete medium (exflagellation medium supplemented with $20 \%$ heat inactivated foetal bovine serum), $10 \mathrm{U} / \mathrm{mL}$ penicillin and $10 \mu \mathrm{g} / \mathrm{mL}$ streptomycin were added to a 96-well microplate (Nunc, Denmark). 


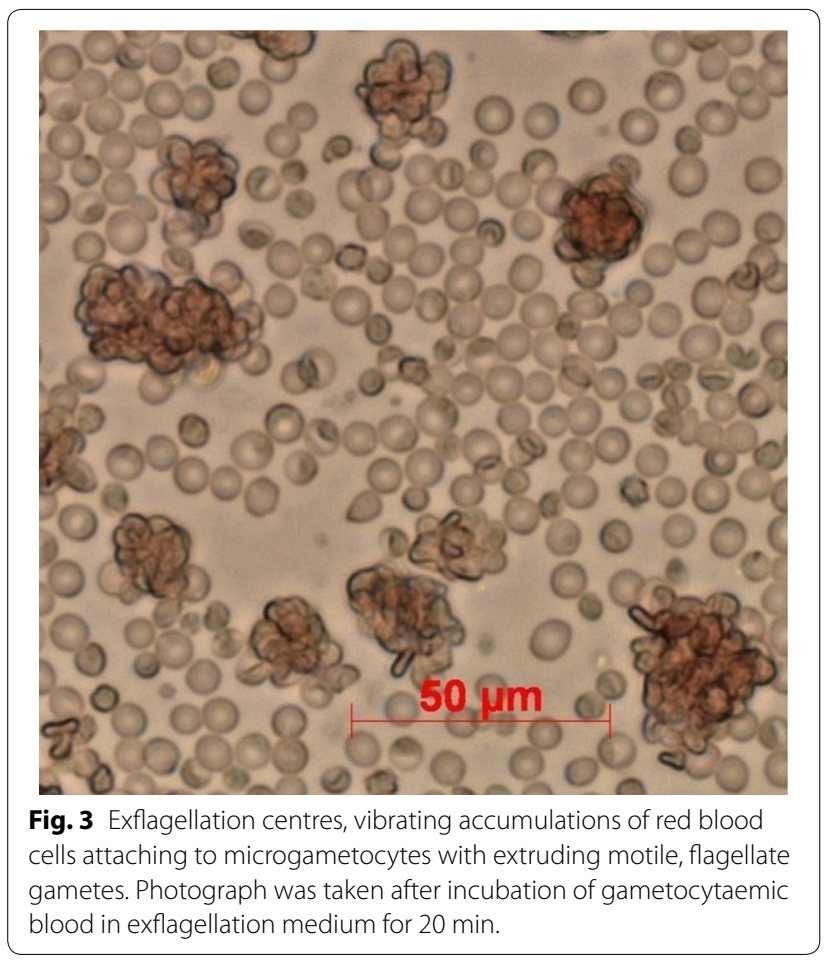

Dimethyl sulfoxide (DMSO, a solvent dissolve extracts/ molecules) and PBS a solvent for the aqueous extract were used as controls, at a maximum concentration of $0.2 \%$. Twenty microlitre of diluted $V$. amygdalina extracts, fractions or molecules were then added to the microplate wells to obtain the desired test concentrations $(3-50 \mu \mathrm{g} / \mathrm{mL})$. Then, $20 \mu \mathrm{L}$ of blood obtained from gametocytaemic mice by cardiac puncture were transferred to the test microplates and mixed swiftly. The plates were then incubated at $19^{\circ} \mathrm{C}$ for $40 \mathrm{~h}$. At the end of the incubation, the plate contents was mixed and $10 \mu \mathrm{L}$ of cell suspension from each well were withdrawn, diluted with serum-free medium at a ratio of 1:25-1:50 and transferred to a fresh 96-well microplate. This dilution step allowed to obtain - after cell settlement-a RBC monolayer, allowing accurate microscopic counts. GFPexpressing zygotes and ookinetes were visualized using a fluorescence microscope (400× magnification) (Fig. 4) and quantified with the help of an ocular grid. ESS counts were performed in a series of fields along the well diameter. Percent inhibition of ESS development was calculated as follows:

Percent inhibition of ESS development

$=\left(1-\frac{\text { Mean ESS count in test wells }}{\text { Mean ESS count in solvent control wells }}\right) \times 100$

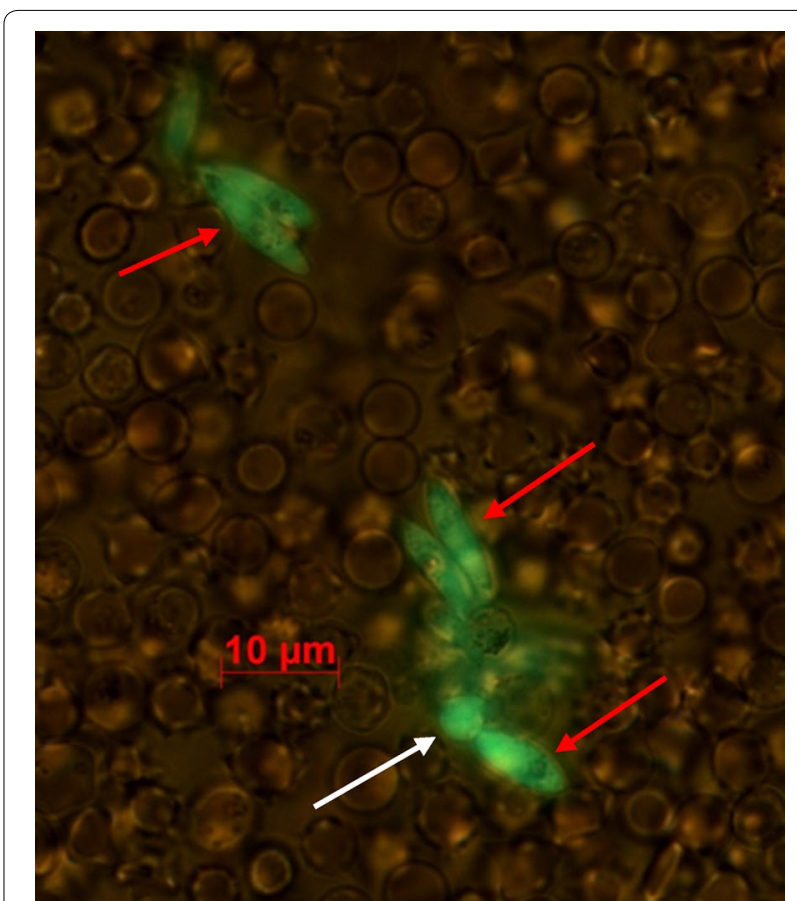

Fig. 4 Early sporogonic stages: spherical zygote (white arrow) and elongated ookinetes (red arrows).

Each substance was tested in 3-6 replicate wells and experiments were repeated at least twice.

Extracts/molecules demonstrating a $>80 \%$ inhibition at $50 \mu \mathrm{g} / \mathrm{mL}$ were dose ranged to determine the $\mathrm{IC}_{50}$ values.

\section{Evaluation of effects on exflagellation of male gametocytes in vitro}

Extracts/molecules found active in the ODA were tested in an exflagellation assay to assess stage-specific effects on male gametogenesis. The exflagellation assay was carried out according to the protocol illustrated above [55, 56]. Mice were treated with phenylhydrazine and infected with $P$. berghei ANKA. On day 4 post-infection, $5 \mu \mathrm{L}$ tail blood were collected and resuspended in $140 \mu \mathrm{L}$ exflagellation medium containing $50 \mu \mathrm{g} / \mathrm{mL}$ Ver-EtOH or $50 \mu \mathrm{M}$ vernodalol, dissolved in DMSO to a maximum DMSO concentration of $0.2 \%$. DMSO and azadirachtin A were used as negative and positive controls, respectively [14]. The number of exflagellation centres per 1,000 RBCs, as an index of microgametogenesis $[57,58]$, were counted under the microscope (400× magnification), $20 \mathrm{~min}$ after mounting the slide chambers. For each concentration of test extract/molecule triplicate slides were counted (Fig. 3). 


\section{Assessment of effects on the feeding capacity of Anopheles stephensi}

The impact of Ver-EtOH on An. stephensi blood feeding was assessed to evaluate whether a reduction in mosquito infection in the in vivo transmission blocking experiment might be the result of decreased blood intake and hence ingestion of a reduced number of gametocytes. Feeding capacity was estimated by measuring the haematin content in the rectal fluid excreted by female mosquitoes during blood feeding. Briefly, narcotized mice, treated with $100 \mathrm{mg} / \mathrm{kg}$ extract or solvent control (i.p.) $1 \mathrm{~h}$ before, were placed on top of mosquito cages and the rectal fluid from feeding mosquitoes was collected in plastic Petri dishes (15 cm diameter), previously placed inside the mosquito cage. The content of each Petri dish was then dissolved in $20 \mathrm{~mL}$ of $0.1 \mathrm{M} \mathrm{NaOH}$ and incubated overnight to allow for the conversion of haemoglobin to haematin [59]. To remove debris, the mixture was centrifuged at $13,000 \mathrm{rpm}$ for $10 \mathrm{~min}$. Supernatant samples were then serially diluted twofold in a 96-well microplate and the absorbance was measured at $392 \mathrm{~nm}$ wavelength using a FLUOstar Omega microplate reader (BMG Labtech, Germany). Commercial haemin (SigmaAldrich) was dissolved in $0.1 \mathrm{M} \mathrm{NaOH}$ in order to derive haematin solutions [60] for the preparation of a calibration curve. The concentration of haematin in the diluted samples was then determined by extrapolating the optical density values onto the standard curve.

\section{Cytotoxicity assessment}

General cell toxic effects of $V$. amygdalina constituents were assessed on human colon carcinoma cell line HCT116 and human endothelial cell line (EA.hy926). HCT116 was cultured in RPMI1640 medium with $2 \mathrm{mM}$ L-glutamine, $100 \mathrm{IU} / \mathrm{mL}$ penicillin, $100 \mu \mathrm{g} / \mathrm{mL}$ streptomycin, and supplemented with $10 \%$ heat-inactivated foetal bovine serum (HI-FBS; PAA Laboratories $\mathrm{GmbH}$, Austria). EA.hy926 was cultured in Dulbecco's Modified Eagle's Medium (DMEM) with $2 \mathrm{mM}$ L-glutamine, $100 \mathrm{IU} / \mathrm{mL}$ penicillin, $100 \mu \mathrm{g} / \mathrm{mL}$ streptomycin and supplemented with $10 \%$ HI-FBS. Cells were cultured in a humidified atmosphere at $37^{\circ} \mathrm{C}$ in presence of $5 \% \mathrm{CO}_{2}$.

The cytotoxic activity of extracts, fractions and pure compounds from $V$. amygdalina leaves was measured by the 3-(4,5-dimethylthiazol-2-yl)-2,5-diphenyltetrazolium bromide (MTT) assay [61]. Briefly, $100 \mu \mathrm{L}$ aliquots of cell suspensions were plated at a density of $2 \times 10^{4}$ cells/ $\mathrm{mL}$ in flat-bottomed 96-well microplates (Falcon, Becton Dickinson Labware, USA). After $24 \mathrm{~h}$, cells were exposed to compounds, fractions and extracts at concentrations ranging from 0.78 to $200 \mu \mathrm{g} / \mathrm{mL}$, or $0.1 \%$ DMSO as control. Cell cultures were incubated at standard conditions for $72 \mathrm{~h}$. At the end of the incubation, $10 \mu \mathrm{L} /$ well of MTT (5 mg/mL in phosphate-buffered saline) were added to the plates, and these were further incubated for $4 \mathrm{~h}$ at $37^{\circ} \mathrm{C}$. Formazan crystals, produced by viable cells, were dissolved in $100 \mu \mathrm{L}$ of DMSO after removal of the medium from the wells. Absorbance was measured at $540 \mathrm{~nm}$ using a FLUOstar Omega microplate reader. Cytotoxicity was expressed as the concentration of extracts, fractions or pure compounds inhibiting cell growth by $50 \%\left(\mathrm{IC}_{50}\right)$. The selectivity index $(\mathrm{SI})$ was derived by dividing the $\mathrm{IC}_{50}$ value for mammalian cells by that obtained in the ODA against ESS.

\section{Assessment of transmission blocking activity on Plasmodium falciparum field isolates Study site and recruitment of gametocyte carriers}

The study was conducted in the area of Bobo-Dioulasso (Southwest Burkina Faso) during the high transmission season (September to October) in 2013 [15]. Gametocyte positive blood samples for the direct membranefeeding assay (DMFA) were obtained from children aged 5-11 years. Totally 875 children were examined during seven screening events. At each survey the children were clinically examined for the presence of chronic diseases and acute infections including signs of severe malaria. Finger-prick blood was collected for the preparation of thick smears and measurement of haemoglobin using Hemocue (AB Leo Diagnostics, Helsingborg, Sweden). Medication history, namely use of anti-malarial drugs during the last two weeks and hypersensitivity history, was recorded.

Giemsa-stained thick smears were examined at the laboratory of the "Institut de Recherche en Sciences de la Santé" (IRSS) on the same day. On each slide 100 fields were screened for the presence of Plasmodium parasites. On positive slides, asexual parasite and gametocyte numbers were determined per 200 and 1,000 leukocytes, respectively. Gametocytaemia and parasitaemia were then expressed as gametocytes $/ \mu \mathrm{L}$ and total number of parasites $/ \mu \mathrm{L}$ of blood, referring to 8,000 leukocytes $/ \mu \mathrm{L}$ of blood [15]. Asymptomatic children with P. falciparum gametocytaemia $\geq 40$ gametocytes $/ \mu \mathrm{L}$, parasitaemia $\leq 1,200$ parasites $/ \mu \mathrm{L}$ and negative for other Plasmodium species were selected as blood donors for the DMFA scheduled for the following day.

All parasitologically confirmed malaria cases during screening for the identification of gametocyte donors were treated with a combination of artesunate $(4 \mathrm{mg} / \mathrm{kg}$ body weight) and amodiaquine (10 $\mathrm{mg} / \mathrm{kg}$ body weight), once daily for 3 days.

\section{Test fractions}

Fractions 11, 13, and 14 from the EtOAc phase were selected based on anti-ESS activity obtained in the ODA 
with $P$. berghei and were tested for transmission-blocking activity on P. falciparum isolates.

\section{Direct membrane feeding assay}

The assay involving $P$. falciparum gametocytaemic blood from volunteer individuals and An. coluzzii mosquitoes [15] has been validated by Bousema and colleagues for the assessment of transmission blocking interventions [62]. Batches of about 50 female An. coluzzii mosquitoes were housed in cardboard cups covered with mesh nettings. Aliquots of $500 \mu \mathrm{L}$ gametocytaemic blood containing fractions 11, 13 and 14 from $V$. amygdalina at a concentration of $100 \mu \mathrm{g} / \mathrm{mL}$ were placed in glass feeders and mosquitoes were allowed to feed for $45 \mathrm{~min}$. Unfed mosquitoes were discarded. On day 7 after membrane feeding, all surviving mosquitoes were examined for prevalence and density of oocysts. Mosquito midguts were dissected and mounted in PBS containing $1 \%$ mercurochrome as an oocyst stain. Geometric means of oocyst densities [53] were calculated considering positive mosquitoes only.

\section{Ethical clearance}

The field study involving venous blood collection from children infected with $P$. falciparum was approved by the Ethical Committee of the Centre Muraz and filed under the registration number N/Ref. 003-2009/CE-CM. Parents or guardians provided written informed consent before children were enrolled into the blood sample collection.

The experiments conducted with mice in the animal rearing facilities of the University of Camerino had been examined by the Ethical Committee of the University (COMITATO ETICO DI ATENEO Protezione degli Animali utilizzati a fini sperimentali o altri fini scientifici CEAPA) to be compliant with the Italian Legislative Decree on the "use and protection of laboratory animals" (D. Lgs. 116 of 10/27/92, paragraph 7) and had been approved by the Counsel of the School of Pharmacy, University of Camerino.

\section{Statistical analyses}

Excel 2007 spreadsheet (Microsoft office) and GraphPad Prism 6 statistical software (GraphPad Software, San Diego, CA, USA) were used for data analysis. Normally distributed data, namely gametocyte densities, haematin values, ESS counts and derived \% inhibition values, were expressed as arithmetic means and $95 \%$ confidence intervals $(95 \% \mathrm{CI})$, whereas oocyst densities among infected mosquitoes were expressed as geometric means and 95\% CI. The independent samples Student's $t$-test was used to compare means and Fisher's exact test to compare categorical data. The a priori statistical significance level $(\alpha)$ was set at 0.05 .

\section{Results}

\section{Gametocytocidal activity in vivo}

On day 7 after exposure to infectious mosquito bites, mice treated orally with $500 \mathrm{mg} / \mathrm{kg}$ Ver- $\mathrm{H}_{2} \mathrm{O}$ for 9 days showed a 46.8 and $45.4 \%$ reduction in macrogametocyte densities in two independent experiments. In the first one, mean counts of 48 and 25.5 macrogametocytes/2,500 infected red blood cells (iRBCs) were recorded in control and treatment mice, respectively, and respective counts of 42.7 and $23.3(\mathrm{p}<0.05)$ were obtained in the replicate experiment. Ver- $\mathrm{H}_{2} \mathrm{O}$ appeared to affect also microgametocytes but a significant reduction of male sexual forms $(\mathrm{p}<0.05)$ was observed only in one of the two experiments. VerEtOH treatment at $500 \mathrm{mg} / \mathrm{kg}$ did not impact significantly on macro- or microgametocyte densities (Table 1).

Examining the same slides of the two experiments for asexual forms, Ver-EtOH was found to reduce parasitaemia by $59.2 \%$ (95\% CI $52.6-65.7 \%$ ). Parasitaemia in the groups treated with Ver-EtOH amounted 3.6 and $8.7 \%$ in the control groups $(\mathrm{p}<0.05)$. Ver- $\mathrm{H}_{2} \mathrm{O}$ reduced parasitaemia by $33.6 \%$ (95\% CI $26.7-40.2 \%$ ), parasitaemia values of 5.8 and $8.7 \%$ were recorded in the treatment and control groups, respectively $(\mathrm{p}<0.05)$.

Table 1 Effect of Vernonia amygdalina leaf extracts on Plasmodium berghei gametocyte densities

\begin{tabular}{llll}
\hline Treatment groups & Experiment $^{\mathbf{a}}$ & $\begin{array}{l}\text { Microgametocytes per } \\
\mathbf{2 , 5 0 0 ~ I R B C s}(\mathbf{9 5 \%} \text { CI) }\end{array}$ & $\begin{array}{l}\text { Macrogametocyte per } \\
\mathbf{2 , 5 0 0 ~ I R B C s}(\mathbf{9 5 \%} \text { CI) }\end{array}$ \\
\hline Ver-EtOH & 1 & $6.7(5.4-8.0)$ & $40.3(35.9-44.7)$ \\
& 2 & $6.8(5.6-8.0)$ & $38.4(32-44.8)$ \\
Ver- $\mathrm{H}_{2} \mathrm{O}$ & 1 & $5.5(4.9-6.1)$ & $25.5(22.8-28.2)^{*}$ \\
& 2 & $5.3(4.9-5.7)^{*}$ & $23.3(20.7-26.0)^{*}$ \\
Control & 1 & $7.2(5.1-9.3)$ & $48(34.7-61.3)$ \\
& 2 & $8.5(6.1-10.9)$ & $41.7(33.6-49.7)$ \\
\hline
\end{tabular}

Data are presented as arithmetic means with $95 \%$ confidence intervals $(95 \% \mathrm{Cl})$.

IRBCs infected red blood cells, Ver-EtOH ethanolic V. amygdalina leaf extract, Ver- $\mathrm{H}_{2} \mathrm{O}$ aqueous V. amygdalina leaf extract * $\mathrm{p}<0.05$ with respect to their control.

a Numbers 1 and 2 refer to the two replicate experiments each involving treatment and control groups consisting of six mice each. 


\section{Transmission blocking activity in vivo}

Both, Ver-EtOH and Ver- $\mathrm{H}_{2} \mathrm{O}$, when administered to mosquitoes through a blood meal on treated gametocytaemic mice, impacted on the vector infection. Ver- $\mathrm{H}_{2} \mathrm{O}$ reduced oocyst density by $54.7 \%$ ( $95 \%$ CI $35.3-72.1)$. The mean number of oocysts amounted 266 in control mosquitoes fed on solvent-treated mice and 123 in the mosquitoes fed on mice treated with Ver- $\mathrm{H}_{2} \mathrm{O}(\mathrm{p}<0.05)$. The number of uninfected mosquitoes (infection prevalence) was similar in Ver- $\mathrm{H}_{2} \mathrm{O}$ and control mosquitoes (Table 2). Ver-EtOH reduced both infection prevalence and intensity. The prevalence amounted $71.4 \%$ (95\% CI 61.381.5\%) in mosquitoes fed on Ver-EtOH, compared with 97.6\% (95\% CI 94.4-100.9\%) in controls, corresponding to a significant reduction of $27 \%(\mathrm{p}<0.05)$. Among the infected mosquitoes, the mean oocyst density was 374 in control mosquitoes versus 37 in Ver-EtOH treated mosquitoes, resulting in a $90 \%$ reduction of oocyst numbers (95\% CI 83.2-96.8\%; $\mathrm{p}<0.05)$ (Table 2).

In Ver-EtOH experiments, the feeding capacity of treatment and control mosquitoes was estimated by measuring the amount of haematin excreted with the rectal fluid. Mosquitoes offered a blood meal on mice treated with Ver-EtOH took slightly but not significantly less blood compared with mosquitoes fed on control mice. The mean amount of haematin was $5 \mu \mathrm{g}$ per mosquito $(95 \%$ CI $4.34-5.66 \mu \mathrm{g})$ in those having fed on Ver-EtOH treated mice versus $6.2 \mu \mathrm{g}$ per mosquito (95\% CI $5.2-$ $7.2 \mu \mathrm{g})$ in the control group ( $\mathrm{p}=0.13)$. Similar results were obtained in a replicate experiment, yielding a value of $8.6 \mu \mathrm{g}$ per fed mosquito (95\% CI 7.53-9.67 $\mu \mathrm{g}$ ) in the extract-exposed group versus $11.1 \mu \mathrm{g}$ per mosquito $(95 \%$ CI 9.6-12.6 $\mu \mathrm{g})$ in controls $(\mathrm{p}=0.06)$. Five microgram approximately corresponds to the haematin content of $1 \mu \mathrm{L}$ blood.

\section{Impact on the development of early sporogonic stages in vitro \\ Ethanolic and aqueous extracts}

The two extracts found active in our in vivo transmission blocking study (Ver-EtOH and $\mathrm{Ver}-\mathrm{H}_{2} \mathrm{O}$ ) were investigated in vitro for inhibition of ESS, hypothesizing that the ESS developing in the mosquito midgut in the first $24 \mathrm{~h}$ after blood ingestion, are likely targets for the bioactive extract metabolites. Ver-EtOH tested at the initial screening dose of $50 \mu \mathrm{g} / \mathrm{mL}$ was found to inhibit ESS development by $81.3-96.2 \%$, while the aqueous extract showed no inhibitory activity (Table 3 ).

Dose range experiments performed with Ver-EtOH allowed us to determine an $\mathrm{IC}_{50}$ value of $15.4 \mu \mathrm{g} / \mathrm{mL}$ (95\% CI $12.7-18.8 \mu \mathrm{g} / \mathrm{mL})$. Enumerating zygotes and ookinetes separately, the proportion of ookinetes, which include zygotes initiating elongation and developing to fully mature ("banana shaped") ookinetes, was found to be reduced at the highest Ver-EtOH test concentration. In control wells $90-98 \%$ of zygotes were recorded to undergo ookinete development, whereas in those to which Ver-EtOH was added at $50 \mu \mathrm{g} / \mathrm{mL}$ only about one fifth to one half of total ESS presented elongated forms (Fig. 5).

Table 2 Effect of ethanolic and aqueous leaf extracts of Vernonia amygdalina on Plasmodium berghei oocyst development in Anopheles stephensi mosquitoes

\begin{tabular}{|c|c|c|c|c|}
\hline Group & Mouse ID ${ }^{a}$ & $\begin{array}{l}\text { Prevalence of infected mosquitoes } \\
\text { (infected/total examined) }\end{array}$ & $\begin{array}{l}\text { Oocyst density by mouse } \\
\text { replicate }(95 \% \mathrm{CI})\end{array}$ & $\begin{array}{l}\text { Oocyst density by treatment } \\
\text { group }(95 \% \mathrm{CI})\end{array}$ \\
\hline \multirow[t]{3}{*}{ Ver-EtOH } & 1 & $76.9(20 / 26)$ & $27(13-57)$ & $37(26-53)^{*}$ \\
\hline & 2 & $29.4(5 / 17)$ & $12(5-28)$ & \\
\hline & 3 & $88.2(30 / 34)$ & $56(32-96)$ & \\
\hline \multirow[t]{3}{*}{ Sol-EtOH } & 4 & $100(34 / 34)$ & $417(297-585)$ & $374(297-467)$ \\
\hline & 5 & $96.4(27 / 28)$ & 439 (319-605) & \\
\hline & 6 & $95.7(22 / 23)$ & $260(152-447)$ & \\
\hline \multirow[t]{3}{*}{ Ver- $\mathrm{H}_{2} \mathrm{O}$} & 7 & $100(20 / 20)$ & $72(45-103)$ & $123(83-149)^{*}$ \\
\hline & 8 & $100(20 / 20)$ & $151(101-161)$ & \\
\hline & 9 & $100(20 / 20)$ & $143(104-182)$ & \\
\hline \multirow[t]{3}{*}{ Sol- $\mathrm{H}_{2} \mathrm{O}$} & 10 & $100(20 / 20)$ & $272(225-319)$ & $266(200-300)$ \\
\hline & 11 & $100(20 / 20)$ & $242(186-298)$ & \\
\hline & 12 & $100(20 / 20)$ & $237(190-284)$ & \\
\hline
\end{tabular}

The oocyst densities (geometric mean of oocysts/mosquito) were calculated on oocyst positive mosquitoes only.

Ver-EtOH ethanolic V. amygdalina leaf extract, Ver- $\mathrm{H}_{2} \mathrm{O}$ aqueous $\mathrm{V}$. amygdalina leaf extract, Sol-EtOH and Sol- $\mathrm{H}_{2} \mathrm{O}$ are solvent controls for the ethanolic and aqueous extract, respectively.

* Oocyst density in extract treated groups significantly different with respect to the solvent controls; $\mathrm{P}<0.05$.

${ }^{a}$ Each number represents one gametocytaemic treatment or control mouse used for the infection of a separate batch of mosquitoes (100-150 females per mouse). 
Table 3 Impact of Vernonia amygdalina leaf extracts on the development of early sporogonic stages in vitro

\begin{tabular}{|c|c|c|c|}
\hline Test agents & Experiment $^{a}$ & Mean ESS counts $(95 \% \mathrm{Cl})^{b}$ & $\begin{array}{l}\text { Percentage inhibition } \\
\text { of ESS }(95 \% \mathrm{Cl})\end{array}$ \\
\hline \multirow[t]{4}{*}{ Ver-EtOH } & 1 & $53(46-60)$ & $81.3(79.1-83.7)$ \\
\hline & 2 & $11(3-19)$ & $96.2(93.4-99.1)$ \\
\hline & 3 & $18(15-20)$ & $87.5(85.8-89,14)$ \\
\hline & 4 & $45(41-50)$ & $88(86.7-89.4)$ \\
\hline \multirow[t]{4}{*}{ Sol-EtOH } & 1 & $285(239-332)$ & \\
\hline & 2 & $283(261-306)$ & \\
\hline & 3 & $141(120-163)$ & \\
\hline & 4 & $378(310-446)$ & \\
\hline \multirow[t]{2}{*}{ Ver- $\mathrm{H}_{2} \mathrm{O}$} & 5 & $51(42-60)$ & $14(5-23.1)$ \\
\hline & 6 & $23(14-32)$ & $38.7(14.2-63.3)$ \\
\hline \multirow[t]{2}{*}{ Sol- $\mathrm{H}_{2} \mathrm{O}$} & 5 & $59(51-68)$ & \\
\hline & 6 & $37(32-42)$ & \\
\hline
\end{tabular}

Ver-EtOH and Ver- $\mathrm{H}_{2} \mathrm{O}$ were tested at $50 \mu \mathrm{g} / \mathrm{mL}$.

Data are presented as mean early sporogonic stages (ESS) counts calculated from triplicate wells and percentages of ESS inhibition referred to solvent controls. Both parameters are presented with $95 \%$ confidence intervals $(95 \% \mathrm{CI})$.

Ver-EtOH ethanolic V. amygdalina leaf extract, Ver- $\mathrm{H}_{2} \mathrm{O}$ aqueous V. amygdalina leaf extract, Sol-EtOH (dimethyl sulfoxide at $0.2 \%$ ) and Sol- $\mathrm{H}_{2} \mathrm{O}$ (phosphate buffered saline) are solvent controls for the ethanolic and aqueous extract, respectively.

a Each number represents one experiment conducted with gametocytaemic blood from a different mouse.

b Mean ESS counts are rounded to the nearest whole numbers.

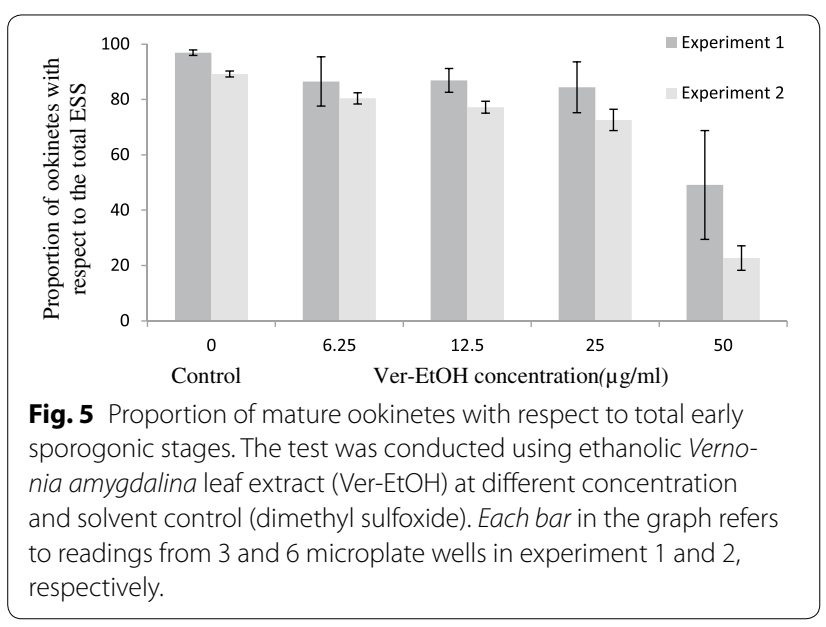

\section{Phases and fractions}

Following the congruent results emerging from the in vitro and in vivo transmission blocking experiments with the Ver-EtOH, bioassay guided fractionation studies were undertaken to identify the molecule(s) responsible for the observed activity against EES.

Ver- $\mathrm{MeOH}$ (for the procedures of chemical analysis, $\mathrm{MeOH}$ was preferred to $\mathrm{EtOH}$ as extraction solvent, since they have practically identical extracting efficiency) revealed moderate in vitro activity against ESS, at the initial screening dose of $50 \mu \mathrm{g} / \mathrm{mL}$, consisting in a $51-68.3 \%$ ESS development inhibition (Table 4). The $\mathrm{BuOH}$ phase separated from Ver-MeOH displayed higher inhibitory activity (>86\%). This fraction, however, was found to be cytotoxic to RBCs provoking evident haemolysis at this dosage. The EtOAc phase displayed an inhibition range of $58.3-79.1 \%$, whereas the water phase showed poorly reproducible effects (Table 4). Based on these results, the EtOAc phase was selected for further fractionation, whereas the $\mathrm{BuOH}$ and $\mathrm{H}_{2} \mathrm{O}$ phases were not considered for further study due to cytotoxicity, for the former, and doubts on the specificity of the effects displayed by the latter. The EtOAc phase was subjected to medium pressure liquid chromatography (MPLC) and 14 fractions were obtained. Based on proton-NMR preliminary analysis, four fractions containing fatty acids and/or triglycerides were not considered for testing, while ten fractions were screened in vitro for impact on ESS development. Fractions 2, 3, 5, 8, 9, and 10 did not exhibit relevant reproducible activity at $50 \mu \mathrm{g} / \mathrm{mL}$, whereas fractions 11 to 14 caused almost complete ESS inhibition (>90\%). These fractions were eluted with mobile phases of different polarity, namely fr 11 [ $n$-hexane:EtOAc (1:1 to 7:11)], fr 12 [ $n$-hexane:EtOAc (7:11 to 1:4)], fr 13 [EtOAc] and fr 14 [EtOAc:MeOH (1:1)] (Table 5).

Transmission blocking activity of Vernonia amygdalina leaf fractions against Plasmodium falciparum field isolates

Fractions demonstrating activity against $P$. berghe $i$ ESS in the ookinete development assay were tested for confirmation of transmission blocking activity on field isolates of the human malaria parasite $P$. falciparum. All fractions affected the sporogonic development of $P$. falciparum in 
Table 4 Impact of Vernonia amygdalina leaf methanolic extract and derived phases on the development of early sporogonic stages

\begin{tabular}{|c|c|c|c|}
\hline Test agents & Experiment $^{\mathrm{a}}$ & Mean ESS $(95 \% \mathrm{Cl})^{\mathrm{b}}$ & $\begin{array}{l}\text { Percentage inhibition } \\
\text { of ESS }(95 \% \mathrm{Cl})\end{array}$ \\
\hline \multirow[t]{5}{*}{ Ver-MeOH } & 1 & $13(9-18)$ & $51.0(34.2-67.8)$ \\
\hline & 2 & $4(3-6)$ & $68.3(58.7-77.9)$ \\
\hline & 3 & $41(34-47)$ & $57.5(50.6-64.4)$ \\
\hline & 4 & $105(92-118)$ & $51.9(45.9-57.9)$ \\
\hline & 5 & $57(47-66)$ & $57.9(50.9-64.9)$ \\
\hline \multicolumn{4}{|l|}{ Phases from methanolic extract } \\
\hline \multirow[t]{5}{*}{ Water } & 1 & $13(7-20)$ & $51.0(26.6-75.4)$ \\
\hline & 2 & $5(2-7)$ & $65.9(46.7-85.0)$ \\
\hline & 3 & $8(0-8)$ & $91.6(86.2-97.1)$ \\
\hline & 4 & $115(76-154)$ & $47.5(29.8-65.1)$ \\
\hline & 5 & $76(59-93)$ & $43.6(31-56.1)$ \\
\hline \multirow[t]{5}{*}{ Ethylacetate } & 1 & $11(10-13)$ & $58.3(52.0-64.7)$ \\
\hline & 2 & $4(2-5)$ & $73.2(60.5-85.8)$ \\
\hline & 3 & $20(15-25)$ & $79.1(73.7-84.5)$ \\
\hline & 4 & $76(40-112)$ & $65.4(49.0-81.9)$ \\
\hline & 5 & $48(37-59)$ & $64.1(55.9-72.3)$ \\
\hline \multirow[t]{5}{*}{ Butanol } & 1 & $1(0-3)$ & $95.1(88.7-100)$ \\
\hline & 2 & $1(1-2)$ & $90.2(85.5-95.0)$ \\
\hline & 3 & $2(1-4)$ & $97.6(95.8-99.4)$ \\
\hline & 4 & $15(7-22)$ & $93.3(89.9-96.7)$ \\
\hline & 5 & $18(14-23)$ & $86.4(82.9-89.9)$ \\
\hline \multirow[t]{5}{*}{ Solvent control (0.2\% DMSO) } & 1 & $27(22-33)$ & \\
\hline & 2 & $14(9-19)$ & \\
\hline & 3 & $96(85-106)$ & \\
\hline & 4 & $219(198-240)$ & \\
\hline & 5 & $135(111-158)$ & \\
\hline
\end{tabular}

Methanolic V. amygdalina leaf extract and its butanol, ethylacetate and water phases were tested at $50 \mu \mathrm{g} / \mathrm{mL}$.

Data are presented as mean counts of early sporogonic stages (ESS) calculated from triplicate wells and percentages of ESS inhibition referred to solvent control. Both parameters are presented with $95 \%$ confidence intervals $(95 \% \mathrm{Cl})$.

Ver-MeOH methanolic extract of $\mathrm{V}$. amygdalina leaves.

${ }^{a}$ Each number represents one experiment conducted with gametocytaemic blood from a different mouse.

b Mean ESS counts are rounded to the nearest whole number.

An. coluzzii mosquitoes when administered to females by membrane feeding, at $100 \mu \mathrm{g} / \mathrm{mL}$.

The number of infected mosquitoes was reduced upon treatment with fraction 11, 13 and 14, however prevalence values varied conspicuously across replicate experiments (Table 6). In control mosquitoes fed on DMSO-supplemented gametocytaemic blood, oocyst prevalence ranged from 30 to $50 \%$. Fraction 13 was found to block mosquito infection in one replicate experiment and to significantly reduce oocyst prevalence to 6.5 and $8.3 \%$ in the other two. A significant reduction in oocyst prevalence was also recorded with fraction 11 and 14 in two out of the three replicate experiments. Fraction 11 inhibited oocyst development completely in one occasion (Table 6; Fig. 6). Oocyst density, assessed on positive midguts only, was reduced overall by about a half in treated mosquitoes (Table 6; Fig. 6).

\section{Activity of pure compounds from Vernonia amygdalina molecules against Plasmodium berghei early sporogonic stages}

HPLC purification and subsequent NMR-based structural characterization of the constituents of the active fractions allowed the identification of the sesquiterpene lactone vernolide as the major compound of fraction 11 and 12 and vernodalol (Fig. 1) of fractions 13 and 14. The two compounds were tested in the ODA at $50 \mu \mathrm{M}$, revealing vernodalol as the most active molecule, inhibiting ESS development by 70-90\%. Vernolide showed weak and variable inhibitory activity (Table 7). Dose range 
Table 5 Inhibitory activity of ethylacetate phase fractions from Vernonia amygdalina leaves against early sporogonic stages

\begin{tabular}{|c|c|c|c|}
\hline Test agents & Experiment $^{a}$ & Mean ESS counts $(95 \% \mathrm{Cl})^{\mathrm{b}}$ & Percentage inhibition of ESS $(95 \% \mathrm{Cl})$ \\
\hline \multirow[t]{3}{*}{ Fraction-2 } & 1 & $27(17-37)$ & $0.7(0-38.2)$ \\
\hline & 3 & $80(70-90)$ & $16.0(5.7-26.4)$ \\
\hline & 4 & $221(159-281)$ & $0(0-27.5)$ \\
\hline \multirow[t]{3}{*}{ Fraction-3 } & 1 & $27(20-33)$ & $2.0(0-25.6)$ \\
\hline & 3 & $93(77-109)$ & $2.8(0-19.8)$ \\
\hline & 4 & $186(128-245)$ & $14.9(0-41.7)$ \\
\hline \multirow[t]{3}{*}{ Fraction-5 } & 1 & $29(25-33)$ & $0.0(0-6.8)$ \\
\hline & 3 & $40(25-56)$ & $57.8(42.0-73.7)$ \\
\hline & 4 & $215(149-281)$ & $1.8(0-32.1)$ \\
\hline \multirow[t]{3}{*}{ Fraction-7 } & 1 & $23(13-33)$ & $15.4(0-51.0)$ \\
\hline & 3 & $98(84-113)$ & $0(0-12.2)$ \\
\hline & 4 & $224(211-238)$ & $0(0-3.7)$ \\
\hline \multirow[t]{3}{*}{ Fraction-9 } & 1 & $31(19-42)$ & $0.0(0-29.7)$ \\
\hline & 3 & $57(51-63)$ & $40.4(34.2-46.7)$ \\
\hline & 4 & $195(160-229)$ & $11.1(0-26.8)$ \\
\hline \multirow[t]{4}{*}{ Fraction-10 } & 1 & $19(10-27)$ & $31.4(0-63.7)$ \\
\hline & 2 & $6(4-8)$ & $56.1(26.2-86.0)$ \\
\hline & 3 & 71 (57-84) & $26.3(12.5-40.1)$ \\
\hline & 4 & $187(161-213)$ & $14.8(3.0-26.6)$ \\
\hline \multirow{5}{*}{ Fraction-11 } & 1 & $1(0-2)$ & $96.3(92.2-100)$ \\
\hline & 2 & 0 & 100 \\
\hline & 3 & $0(0-1)$ & 99.7 (99-100) \\
\hline & 4 & $1(0-1)$ & $99.7(99.4-100)$ \\
\hline & 5 & 0 & 100 \\
\hline \multirow[t]{5}{*}{ Fraction-12 } & 1 & 0 & 100 \\
\hline & 2 & $1(0-2)$ & $95.1(85.6-100)$ \\
\hline & 3 & $0(0-1)$ & 99.7 (99-100) \\
\hline & 4 & $1(0-2)$ & $99.7(99.1-100)$ \\
\hline & 5 & $0(0-1)$ & $99.8(99.3-100)$ \\
\hline \multirow[t]{5}{*}{ Fraction-13 } & 1 & 0 & 100 \\
\hline & 2 & $0(0-1)$ & $97.6(92.8-100)$ \\
\hline & 3 & 0 & 100 \\
\hline & 4 & $0(0-1)$ & $99.8(99.5-100)$ \\
\hline & 5 & $1(0-2)$ & $99.5(98.5-100)$ \\
\hline \multirow[t]{5}{*}{ Fraction-14 } & 1 & 0 & 100 \\
\hline & 2 & $1(0-2)$ & $92.7(84.4-100)$ \\
\hline & 3 & 0 & 100 \\
\hline & 4 & 0 & 100 \\
\hline & 5 & 0 & 100 \\
\hline \multirow[t]{5}{*}{ Solvent control (0.2\% DMSO) } & 1 & $27(22-33)$ & \\
\hline & 2 & $14(9-19)$ & \\
\hline & 3 & $96(85-106)$ & \\
\hline & 4 & $219(198-240)$ & \\
\hline & 5 & $135(111-158)$ & \\
\hline
\end{tabular}

Fractions from ethylacetate phase were tested at $50 \mu \mathrm{g} / \mathrm{mL}$ concentration.

Data are presented as mean early sporogonic stages (ESS) counts calculated from triplicate wells and percentages of ESS inhibition referred to solvent control. Both parameters are presented with $95 \%$ confidence intervals $(95 \% \mathrm{Cl}$.)

a Each number represents one experiment conducted with gametocytaemic blood from a different mouse.

b Mean ESS counts are rounded to the nearest whole number. 
Table 6 Transmission blocking activity of ethylacetate fractions from Vernonia amygdalina leaves on Plasmodium falciparum isolates

\begin{tabular}{|c|c|c|c|c|}
\hline Blood sample & $\begin{array}{l}\text { Gametocytes } \\
\text { per } \mu \text { L blood }\end{array}$ & Treatment & $\begin{array}{l}\% \text { Prevalence of infected } \\
\text { mosquitoes (infected/total examined) }\end{array}$ & $\begin{array}{l}\text { Oocyst density } \\
(95 \% \mathrm{Cl})\end{array}$ \\
\hline \multirow[t]{4}{*}{1} & 160 & Solvent control & $42.2(19 / 45)$ & $4.2(2.7-6.6)$ \\
\hline & & Fraction-11 & $5.1(2 / 39)^{*}$ & $2.4(1.6-3.6)$ \\
\hline & & Fraction-13 & $8.3(3 / 36)^{*}$ & $1.8(0.6-5.9)$ \\
\hline & & Fraction-14 & $26.2(11 / 42)$ & $3.5(2.3-5.5)$ \\
\hline \multirow[t]{4}{*}{2} & 184 & Solvent control & $29.6(13 / 44)$ & $3.6(1.7-5.5)$ \\
\hline & & Fraction-11 & $32.4(12 / 37)$ & $1.8(0.3-3.3)$ \\
\hline & & Fraction-13 & $6.5(3 / 46)^{*}$ & $1.3(0-2.8)$ \\
\hline & & Fraction-14 & $6.7(3 / 45)^{*}$ & $1.3(0-2.8)$ \\
\hline \multirow[t]{4}{*}{3} & 80 & Solvent control & $50(23 / 46)$ & $3.5(2.2-5.4)$ \\
\hline & & Fraction-11 & $0(0 / 36)^{*}$ & - \\
\hline & & Fraction-13 & $0(0 / 27)^{*}$ & - \\
\hline & & Fraction-14 & $7.3(3 / 41)^{*}$ & 1 \\
\hline
\end{tabular}

Fisher's exact test was used to compare the proportion of infected mosquitoes between control and treatment groups.

${ }^{a}$ Oocyst density was calculated considering infected mosquitoes only. ${ }^{*} \mathrm{P}<0.05$ with respect to the solvent control (dimethyl sulfoxide). Fractions were tested at 100 $\mu \mathrm{g} / \mathrm{mL}$.

experiments conducted with vernodalol allowed to determine an $\mathrm{IC}_{50}$ value of $18.7 \mu \mathrm{M}(95 \% \mathrm{CI} 16.1-21.7 \mu \mathrm{M})$. Evaluating numbers of zygotes and ookinetes separately, the proportion of zygotes initiating elongation or developing to banana shaped mature ookinetes did not appear to be affected by vernolide, vernodalol or the fractions rich in the two molecules (Additional file 1: Table S1, Additional file 2: Table S2).

\section{Effect of vernodalol and ethanolic Vernonia amygdalina leaf extract on microgamete formation}

Vernodalol and Ver-EtOH were tested in the exflagellation assay to assess whether the effect observed on early sporogonic development in the ODA was due to a specific action on microgametogenesis. Vernodalol tested at $50 \mu \mathrm{M}$ and Ver-EtOH at $50 \mu \mathrm{g} / \mathrm{mL}$ demonstrated high inhibitory activity on ESS (Tables 5,8 ), but did not influence microgamete formation. Similar numbers of exflagellation centres per 1,000 RBCs were observed, namely 5.5 (95\% CI 4-7), 4.8 (95\% CI 0-11) and 4.6 (95\% CI 2.3-6.8), for the solvent control, vernodalol $(50 \mu \mathrm{M})$ and Ver-EtOH $(50 \mu \mathrm{g} / \mathrm{mL})$, respectively. For comparison, exflagellation centres counts for azadirachtin A used as a positive control in the assay at $50 \mu \mathrm{M}$ amounted 0.29 (95\% CI 0-0.67).

\section{Cytotoxicity of Vernonia amygdalina extracts, fractions and isolated compounds}

Ver-EtOH and Ver- $\mathrm{MeOH}$ demonstrated a relatively higher cytotoxic effect compared with Ver- $\mathrm{H}_{2} \mathrm{O}$. Fractions active against ESS development, in particular the vernolide-rich fraction 11 and 12, showed strong growth inhibitory effects on both cell lines, HCT116 and EA.hy 926 (Table 8). The selective index (SI) values (ratio of the $50 \%$ inhibitory concentration of mammalian cell viability and of ESS growth) of Ver-EtOH $(9.46 \mu \mathrm{g} / \mathrm{mL}: 15.4 \mu \mathrm{g} /$ $\mathrm{mL})$ and vernodalol $(7.1 \mu \mathrm{M}: 18.7 \mu \mathrm{M})$ were found to be less than one.

\section{Discussion}

Exploratory in vivo studies conducted with $P$. berghei ANKA strain and An. stephensi mosquitoes revealed transmission blocking activity of $V$. amygdalina aqueous $\left(\right.$ Ver- $\left.\mathrm{H}_{2} \mathrm{O}\right)$ and ethanolic (Ver-EtOH) leaf extracts. Anopheles stephensi females, fed on gametocytaemic mice treated with Ver- $\mathrm{H}_{2} \mathrm{O}$ at $500 \mathrm{mg} / \mathrm{kg}$ and Ver-EtOH at $100 \mathrm{mg} / \mathrm{kg}$, developed respectively 55 and $90 \%$ fewer oocysts compared to controls. Subsequent fractionation studies, guided by in vitro assays, revealed activity against the early stages of sporogonic development in four fractions of the ethylacetate phase. Chemical analysis allowed isolation and identification of the two compounds most likely responsible for the transmission blocking activity observed, namely vernodalol and vernolide. These two molecules are sesquiterpene lactones belonging to the structural classes of germacranolides (vernolide) and elemanolides (vernodalol).

Tested as isolated pure compounds, vernodalol and vernolide exhibited moderate to low activity in the in vitro ookinete development assay (ODA). At a concentration of $50 \mu \mathrm{M}(19.6 \mu \mathrm{g} / \mathrm{mL})$ vernodalol inhibited early sporogonic development (ESS) by 70-90\%, while vernolide at the same concentration $(50 \mu \mathrm{M}, 18.1 \mu \mathrm{g} / \mathrm{mL})$ reduced ESS by $9-33 \%$. In line with these data, $V$. amygdalina 


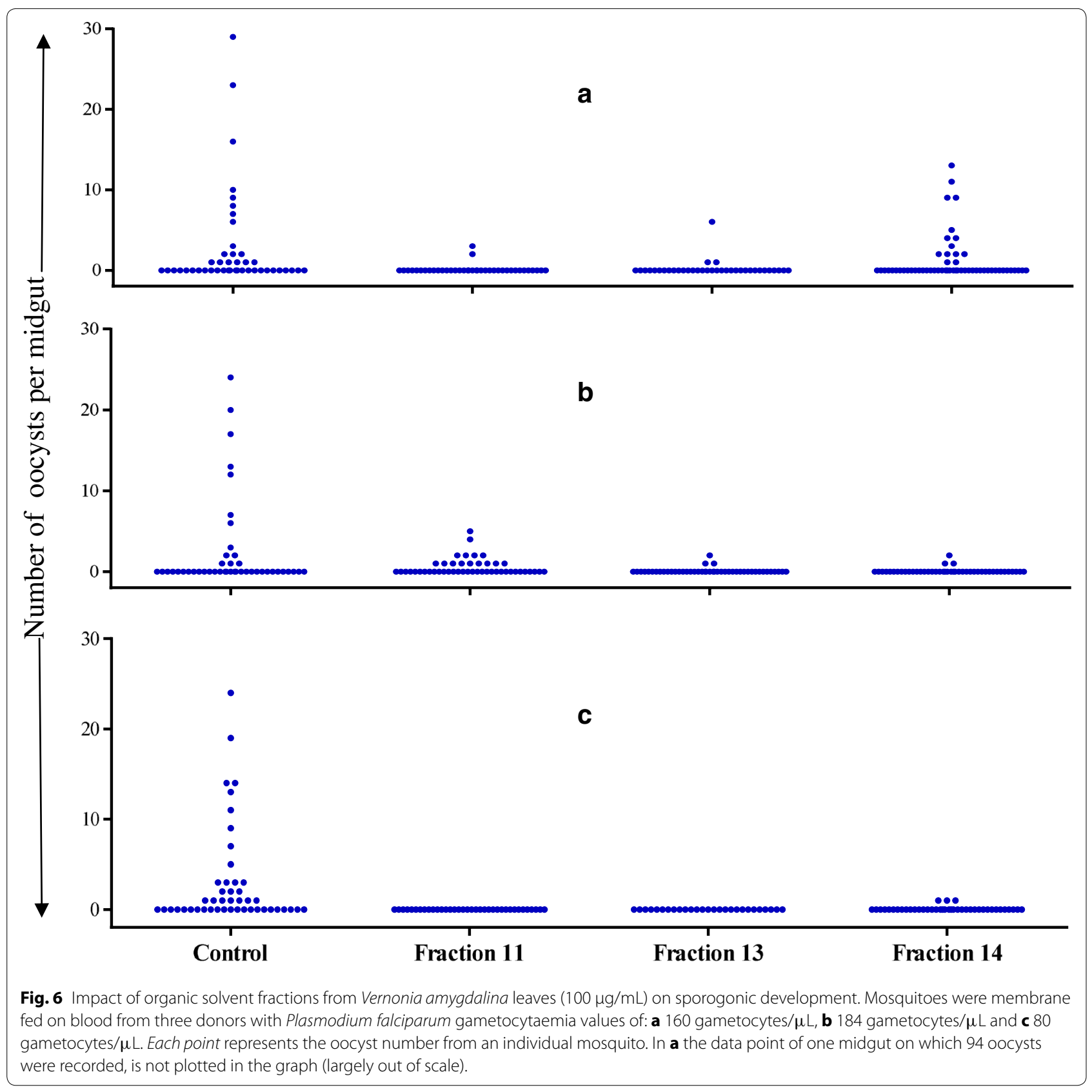

EtOAc fractions composed of almost only vernodalol and vernolide showed evident inhibitory activity in the ODA. Fraction 11 (about 91\% vernolide), fraction 12 (about $50 \%$ vernolide $+50 \%$ vernodalol) and fraction 13 (about $85 \%$ vernodalol) suppressed ESS by $95-100 \%$ when tested at $50 \mu \mathrm{g} / \mathrm{mL}$ (corresponding to amounts of $42-50 \mu \mathrm{g} / \mathrm{mL}$ of vernolide, vernodalol or vernolide + vernodalol).

A relatively stronger activity than expected for its vernodalol and vernolide content, was observed with the EtOAc phase preparation. At $50 \mu \mathrm{g} / \mathrm{mL}$, corresponding to $2.04 \mu \mathrm{g} / \mathrm{mL}$ vernolide and $2.16 \mu \mathrm{g} / \mathrm{mL}$ vernodalol equivalents, the preparation inhibited ESS by $60-80 \%$. This finding may indicate the presence of other bioactive constituents in the EtOAc phase, having a direct effect on ESS or modulating the activity of vernolide and vernodalol. The same interpretation may hold for the results obtained with Ver-EtOH, which was found to inhibit ESS by $80-95 \%$ at $50 \mu \mathrm{g} / \mathrm{mL}$ but contained vernolide and vernodalol at a low concentration of 0.84 and $0.89 \mu \mathrm{g} / \mathrm{mL}$, respectively. Differential counting of 
Table 7 Impact of vernolide and vernodalol on the development of early sporogonic stages in vitro

\begin{tabular}{llcc}
\hline Test compounds & Experiment $^{\mathbf{a}}$ & $\begin{array}{l}\text { Mean ESS } \\
\text { counts (95\% Cl) }\end{array}$ & $\begin{array}{l}\text { Percentage inhibition } \\
\text { of ESS (95\% Cl) }\end{array}$ \\
\hline Vernodalol & 1 & $24(21-26)$ & $79.3(77.3-81.4)$ \\
& 2 & $12(8-16)$ & $89.7(86.4-92.9)$ \\
& 3 & $92(77-107)$ & $69.3(64.3-74.3)$ \\
Vernolide & 1 & $103(90-115)$ & $9.4(0-20.5)$ \\
& 2 & $79(63-95)$ & $30.6(16.7-44.5)$ \\
Solvent control (0.2\% DMSO) & 3 & $201(182-220)$ & $33(26.6-39.3)$ \\
& 1 & $113(93-134)$ & \\
\end{tabular}

Compounds were tested at a concentration of $50 \mu \mathrm{M}$.

a Each number represents one experiment conducted with gametocytaemic blood from a different mouse; ESS counts are means from sextuplicate wells.

b Mean ESS counts are rounded to the nearest whole numbers.

Table 8 Activity of Vernonia amygdalina extracts, fractions and pure compounds on cell viability of a human colon cancer and endothelial cell line

\begin{tabular}{lcc}
\hline Test agents & $\mathbf{I C}_{\mathbf{5 0}}(\mathbf{9 5} \% \mathbf{C l})$ & \\
\cline { 2 - 3 } & HCT116 & EA.hy 926 \\
\hline Leaf extracts $(\mu \mathrm{g} / \mathrm{mL})$ & & \\
Ver-EtOH & $3.66(3.41-3.96)$ & $9.46(8.64-10.36)$ \\
Ver-MeOH & $8.09(7.54-8.67)$ & $16.94(15.55-18.46)$ \\
Ver- $\mathrm{H}_{2} \mathrm{O}$ & $64.34(58.75-70.53)$ & $76.21(58.09-100.00)$ \\
Fractions from methanol extract $(\mu \mathrm{g} / \mathrm{mL})$ & \\
Fraction 11 & $0.17(0.15-0.18)$ & $0.42(0.39-0.45)$ \\
Fraction 12 & $0.33(0.3-0.37)$ & $1.13(0.97-1.31)$ \\
Fraction 13 & $2.41(2.29-2.53)$ & $4.52(4.23-4.82)$ \\
Fraction 14 & $3.86(3.62-4.12)$ & $7.69(7.10-8.32)$ \\
Molecules from fractions $(\mu \mathrm{M})$ & \\
Vernolide & $1.49(1.38-1.61)$ & $3.18(2.97-3.4)$ \\
Vernodalol & $4.97(4.78-5.17)$ & $7.1(6.51-7.74)$ \\
\hline
\end{tabular}

Each value represents the mean of two experiments carried out in quadruplet wells.

Ver-EtOH, Ver-MeOH, and Ver- $\mathrm{H}_{2} \mathrm{O}$ stands for ethanolic, methanolic and aqueous extract of $V$. amygdalina leaves.

HCT 116 human colon carcinoma cell line, EA.hy 926 human (non-tumour) endothelial cell line, 95\% Cl 95\% confidence interval.

zygotes and ookinetes indicated that Ver-EtOH interfered with processes preceding zygote formation. At the highest tested concentration $(50 \mu \mathrm{g} / \mathrm{mL})$, however, an impact on subsequent ookinete maturation was also observed. Interestingly, this was not the case with pure vernolide and vernodalol or with fractions 11 to 13 , consisting almost entirely of these two compounds, an observation suggesting that the two sesquiterpene lactones may interfere with the first processes of sporogonic development, namely gametogenesis and/or macrogamete fertilization.
Exflagellation tests performed with vernodalol and Ver-EtOH allowed to further narrow down the possible target stages. Both the compound and the extract, tested at $50 \mu \mathrm{M}$ and $50 \mu \mathrm{g} / \mathrm{mL}$ respectively, did not interfere with microgamete formation in vitro, suggesting that the processes targeted by $V$. amygdalina transmission blocking components are mainly macrogametogenesis and/or macrogamete fertilization.

Vernolide and vernodalol have been reported to exhibit moderate activity also on asexual blood stages $(39,40)$, inhibiting $P$. falciparum asexual forms by $50 \%$ at a concentration of $1.87-8.4$ and $4.2 \mu \mathrm{M}$, respectively. This multi-stage activity of vernodalol and vernolide raises exciting questions on modes and mechanisms of action of the two sesquiterpene lactones and research focused into this aspect may lead to the discovery of novel multistage drug targets.

In our exploratory in vivo transmission blocking experiment, Ver-EtOH was found to reduce the prevalence of infection in mosquitoes fed on gametocytaemic mice treated (i.p.) with the extract at $100 \mathrm{mg} / \mathrm{kg}$ by about $30 \%$, and oocyst density by $90 \%$. Taking into account the relative amount of vernolide and vernodalol in $\mathrm{Ver}-\mathrm{EtOH}$, at the tested extract dosage mice received approximately $1.7 \mathrm{mg} / \mathrm{kg}$ vernolide and about $1.8 \mathrm{mg} / \mathrm{kg}$ vernodalol. Given this relatively low doses of the transmission blocking compounds, other bioactive molecules in the extract are likely to have contributed directly or indirectly to the transmission blocking effect, as discussed also above relating to Ver-EtOH activity on early sporogonic development in vitro.

The experiments conducted in Burkina Faso with P. falciparum field isolates allowed us to evidence the transmission blocking activity of $V$. amygdalina also against the human malaria parasite. An. coluzzii mosquitoes that had membrane-fed on gametocytaemic blood treated 
with the vernolide and vernodalol-rich EtOAc fractions (fraction 11 and 13, respectively) were less infected and oocyst numbers in positive mosquitoes were reduced by about half. The membrane feeds were supplemented with the fractions at a dosage of $100 \mu \mathrm{g} / \mathrm{mL}$ corresponding to vernolide and vernodalol equivalents of 91.2 and $85 \mu \mathrm{g} /$ $\mathrm{mL}$, respectively. The relatively high dosage needed to achieve a substantial reduction in sporogonic development of $P$. falciparum, taken together with the moderate activity by the pure compounds observed in vitro on $P$. berghei, suggest that neither vernodalol nor vernolide possess the potency required for a drug candidate molecule. On the other hand, significant transmission blocking activity by the Ver-EtOH was evidenced from the in vivo experiments; and the bio-guided fractionation studies revealed a relatively higher in vitro activity of extracts compared to that of the pure compounds, suggesting that the development of a phytomedicine based on vernodalol and vernolide enriched standardized extract may be a more appropriate strategy to pursue.

Artemisinin derivatives have been demonstrated to possess activity against $P$. falciparum gametocytes in vitro [63] and in clinical trials [3], shortening the period of gametocytes circulation in patients treated with ACT [64] and thus decreasing the infection rates of blood seeking mosquitoes. In the current in vivo study, Ver- $\mathrm{H}_{2} \mathrm{O}$ administered to mice at $500 \mathrm{mg} / \mathrm{kg}$ was found to reduce macrogametocyte densities by about $50 \%$. A decrease in microgametocyte numbers was also noticed, reaching significance in one of the two replicates carried out. Since Ver- $\mathrm{H}_{2} \mathrm{O}$ did not exhibit in vitro activity on ESS, but still reduced oocyst densities in mosquitoes when administered to females in vivo through an infectious blood meal, the observed transmission blocking effect might be attributed to the gametocytocidal activity of Ver- $\mathrm{H}_{2} \mathrm{O}$.

Considering the diverging gametocyte biology of $P$. falciparum and P. berghei [65], a validation of the extract's activity on $P$. falciparum gametocytes is the next step to be undertaken. If confirmed, subsequent bio-guided fractionation studies may allow the identification of new gametocytocidal compounds.

Vernonia amygdalina leaves have been the object of various studies evidencing the presence of bio-active secondary metabolites belonging to the classes of saponin, flavonoid, alkaloid, tannin, terpenes, phytosteroids [66-69]. From a comparative study on the profile of $V$. amygdalina secondary metabolites of an aqueous and an ethanol extract emerged an abundant presence of polar polyphenols in the former [70]. This feature has been confirmed by other chemical investigations on Ver- $\mathrm{H}_{2} \mathrm{O}$ extracts $[67,68]$. In the present study, sesquiterpene lactones, namely vernolide and vernodalol, were identified in the less polar phase of Ver-MeOH extract. Considering the similar polarity index of ethanol and methanol [71], it seems correct to assume that Ver-EtOH used in the present study contains sesquiterpene lactones as well. On the contrary, given their poor water solubility, it is very unlikely that sesquiterpene lactones can be present in Ver- $\mathrm{H}_{2} \mathrm{O}$ [72], thus providing chemical bases to the difference in biological responses between Ver-EtOH and Ver- $\mathrm{H}_{2} \mathrm{O}$.

The cytotoxic properties of $V$. amygdalina extracts and compounds have been assessed on various cell lines: $\mathrm{IC}_{50}$ values vary widely with the compounds and type of cell lines used. For instance, a value of $0.11 \mu \mathrm{g} / \mathrm{mL}$ was estimated for vernolide against leukemia cells [73] and 70-75 $\mu \mathrm{g} / \mathrm{mL}$ for vernodalinol against human breast carcinoma cells [33]. Studies assessing in vitro antiplasmodial and cytotoxic activity estimated SI values in the range of 5-10 for ethanol and hydroethanol extracts $[74,75]$, while for a chloroform extract, an SI value of less than one was reported [76]. Pedersen and colleagues determined vernodalol $\mathrm{IC}_{50}$ value against $P$. falciparum blood stages and on a Chinese hamster ovarian cell line of 3.8 and $26.4 \mu \mathrm{g} / \mathrm{mL}$, respectively, implying an SI value of seven [77]. In the present study, both, Ver-EtOH and vernodalol, were found to exhibit SI value below one. Referring to the antiplasmodial drug development consensus, a hit compound should display an SI value of at least ten (a tenfold higher activity against parasites than against a mammalian cell line) to be considered for further development [78]. However, given the interesting multi-stage activity of vernodalol and vernolide, the molecules still are worth to be considered for structure-activity relationship studies aimed at designing compounds with reduced toxicity and enhanced activity against ESS and asexual blood stage parasites. Also, the compounds might be utilized as tools to investigate potential drug targets expressed in multiple life cycle stages.

From studies aimed at elucidating the effects of vernolide on the immune response of melanoma-bearing mice and vernodalin (a sesquiterpene related to vernodalol) on antischistosomal activity in cercaria-infected mice, no serious adverse effect was observed in the animals after administration of vernolide at the immune modulatory dose of $0.5 \mathrm{mg} / \mathrm{kg}$ i.p. [79] and vernodalin at antischistosomal dose of $2.5 \mathrm{mg}$ p.o [40]. In the present study, mice were treated with Ver-EtOH at $100 \mathrm{mg} / \mathrm{kg}$ [vernolide $1.68 \mathrm{mg} / \mathrm{kg}+$ vernodalol $1.78 \mathrm{mg} / \mathrm{kg}$ equivalent dose] i.p. twice and $500 \mathrm{mg} / \mathrm{kg}$ [vernolide $8.4 \mathrm{mg} / \mathrm{kg}$ and vernodalol $8.9 \mathrm{mg} / \mathrm{kg}$ equivalent dose] p.o. for 9 days in the in vivo efficacy experiments. At these doses the extracts appeared tolerable, with no visible signs of toxic effects on the mice. Information on the median lethal dose $\left(\mathrm{LD}_{50}\right)$ of Ver-EtOH and Ver- $\mathrm{H}_{2} \mathrm{O}$ in rodents is also 
available from various studies: $\mathrm{LD}_{50}$ estimates of VerEtOH range from $288 \mathrm{mg} / \mathrm{kg}$ (i.p.) in mice to $1,950 \mathrm{mg} / \mathrm{kg}$ (p.o.) in rats whereas those for Ver- $\mathrm{H}_{2} \mathrm{O}$ from $560 \mathrm{mg} / \mathrm{kg}$ (i.p.) in mice to $3,320 \mathrm{mg} / \mathrm{kg}$ (p.o.) in rats [30, 80-84]. A sub-acute toxicity evaluation of $\mathrm{Ver}-\mathrm{H}_{2} \mathrm{O}$ in rats showed that the extract did not cause any life-threatening adverse effect up to the dose of $2,000 \mathrm{mg} / \mathrm{kg}$ (p.o.) though at a dosage of $1,000 \mathrm{mg} / \mathrm{kg}$ a decrease RBC counts, an increased level of bilirubin and uric acid had been recorded [30]. In a sub-chronic toxicity study of an organic solvent fraction from Ver-MeOH (up to $320 \mathrm{mg} / \mathrm{kg}$, p.o.), no clinical chemistry and histological abnormalities in vital organs were observed in rats [85]. These results are in agreement with our observations on the tolerability of $V$. amygdalina extracts at the doses administered to mice in the current study for the evaluation of in vivo transmission blocking activity of Ver-EtOH $(100 \mathrm{mg} / \mathrm{kg}$ i.p. once daily for 2 days) and the gametocytocidal evaluation $(250 \mathrm{mg} /$ $\mathrm{kg}$ p.o. twice daily for 9 days).

\section{Conclusions}

Previously published work and findings from the present study demonstrate that $V$. amygdalina leaves contain molecules affecting multiple stages of Plasmodium, evidencing its potential for drug discovery and for the development of standardized $V$. amygdalina-based phytomedicines. On the identified hit molecules, primarily vernodalol, chemical modification is recommended to generate a druggable compound with enhanced activity against the blood and sporogonic stages of the malaria parasite and reduced off-target activities. In addition, based on the findings presented here, the development of a multistage phytomedicine, exhibiting both anti-blood stage as well as transmission blocking properties and designed as a preventive treatment to complement existing malaria control tools appears a challenging but feasible goal.

\section{Additional files}

Additional file 1: Table S1. Ratio of ookinete to total early sporogonic stage counts in vernolide and vernodalol treated microplate wells.

Additional file 2: Table S2. Ratio of ookinete to total early sporogonic stage counts in microplate wells treated with Vernonia amygdalina fractions.

\footnotetext{
Authors' contributions

SMA participated in the study design, carried out the experiments, performed the statistical analysis, and drafted the manuscript; ND, GD,EGD, JSO, RKO and SRY participated in the study design and the execution of the experiments; $\mathrm{LQ}$ and MB conducted the cytotoxicity test. AS and OT conducted the phytochemical analysis; LL, GL, GKC, OTS, JBO and FE contributed to the study design and revision of the manuscript; LL, GC and AH, participated in the study design and critically revised the manuscript. All authors read and approved the final manuscript.
}

\section{Author details}

1 School of Pharmacy, University of Camerino, Piazza dei Costanti, 62032 Camerino, MC, Italy. ${ }^{2}$ School of Medicine, College of Health Sciences, Addis Ababa University, Addis Ababa, Ethiopia. ${ }^{3}$ Institut de Recherche enSciences de la Santé, Direction Régionale de l'Ouest, Bobo-Dioulasso, Burkina Faso. ${ }^{4}$ Department of Pharmacy, University of Naples Federico II, Via Montesano 49, 80131 Naples, Italy. ${ }^{5}$ Department of Life Sciences, Imperial College London, London, UK. ${ }^{6}$ Present Address: Discovery Biology, Eskitis Institute for Drug Discovery, Griffith University, Nathan, QLD 4111, Australia.

\section{Acknowledgements}

The authors would like to acknowledge the financial support of the 7th Framework Programme of the European Commission (project 'TransMalariaBloc' no. 223736), the PhD Programme on Malaria and Human Development of the University of Camerino and the Italian Ministry for Education, University and Research (MIUR; PRIN 2008).

\section{Compliance with ethical guidelines}

\section{Competing interests}

The authors declare that they have no competing interests.

Received: 1 December 2014 Accepted: 17 July 2015

Published online: 25 July 2015

\section{References}

1. WHO (2011) World Malaria Report 2011. World Health Organization, Geneva

2. WHO (2014) Fact Sheet No. 94. World Health Organization, Geneva

3. Okell LC, Drakeley CJ, Ghani AC, Bousema T, Sutherland CJ (2008) ReduCtion of transmission from malaria patients by artemisinin combination therapies: a pooled analysis of six randomized trials. Malar J 7:125

4. White NJ (2013) Primaquine to prevent transmission of falciparum malaria. Lancet Infect Dis 13:175-181

5. Abay SM (2013) Blocking malaria transmission to Anopheles mosquitoes using artemisinin derivatives and primaquine: a systematic review and meta-analysis. Parasit Vectors 6:278

6. Wilairatana P, Krudsood S, Tangpukdee N (2010) Appropriate time for primaquine treatment to reduce Plasmodium falciparum transmission in hypoendemic areas. Korean J Parasitol 48:179-182

7. World Health Organization (2012) Updated WHO policy recommendation (October 2012) single dose primaquine as a gametocytocide in Plasmodium falciparum Malaria. 2012(October)

8. Eziefula A, Gosling R, Hwang J, Hsiang M, Bousema T, von Seidlein L et al (2012) Rationale for short course primaquine in Africa to interrupt malaria transmission. Malar J 11:360

9. Achan J, Talisuna AO, Erhart A, Yeka A, Tibenderana JK, Baliraine FN et al (2011) Quinine, an old anti-malarial drug in a modern world: role in the treatment of malaria. Malar J 10:144

10. Weathers PJ, Arsenault PR, Covello PS, Mcmickle A, Teoh KH, Reed DW (2012) Artemisinin production in Artemisia annua: studies in planta and results of a novel delivery method for treating malaria and other neglected diseases. Phytochem Rev 10:173-183

11. Pukrittayakamee S, Chotivanich K, Clemens R, Looareesuwan S, White NJ, Chantra A (2004) Activities of artesunate and primaquine against asexualand sexual-stage parasites in falciparum malaria. Antimicrob Agents Chemother 48:1329-1334

12. Lucantoni L, Yerbanga RS, Lupidi G, Pasqualini L, Esposito F, Habluetzel A (2010) Transmission blocking activity of a standardized neem (Azadirachta indica) seed extract on the rodent malaria parasite Plasmodium berghei in its vector Anopheles stephensi. Malar J 9:66

13. Kleeberg H (2004) Neem based products: registration requirement, regulatory processes and global implications. In: Koul O, Wahab S (eds) Neem Today millenium. Kluwater Academic Publishers, New York, p 114

14. Jones IW, Denholm AA, Ley SV, Lovell H, Wood A, Sinden RE (1994) Sexual development of malaria parasites is inhibited in vitro by the neem extract azadirachtin, and its semi-synthetic analogues. FEMS Microbiol Lett 120:267-273 
15. Yerbanga R, Lucantoni L, Ouédraogo R, Da DF, Yaméogo K, Churcher T et al (2014) Transmission blocking activity of Azadirachta indica and Guiera senegalensis extracts on the sporogonic development of Plasmodium falciparum field isolates in Anopheles coluzzii mosquitoes. Parasit Vectors 7:185

16. Adera T (2003) Beliefs and traditional treatment of malaria in Kishe settlement area, southwest Ethiopia. Ethiop Med J 41:25-34

17. Willcox M (2011) Improved traditional phytomedcines in current use for the clinical treatment of malaria. Planta Med 77:662-671

18. Dori GU (2011) Investigating into South Ethiopian folklore medicine employed for malaria intervention and quantitative method for screening drugs/vaccines acting on pre-erythrocytic stage of Plasmodia. Ph.D. thesis, University of Camerino

19. Gedif T, Hahn HJ (2002) Treatment of malaria in Ethiopian folk medicine. Trop Dr 32:206-209

20. Godesso A (2008) Community's perceptions of malaria and the underlying interventions for its management and control in Jimma town, Oromiya National Regional State. Master's thesis, Addis Ababa University

21. Toyang N, Verpoorte R (2013) A review of the medicinal potentials of plants of the genus Vernonia (Asteraceae). J Ethnopharmacol 146:681-723

22. Lacroix D, Prado S, Kamoga D, Kasenene J, Namukobe J, Krief S et al (2011) Antiplasmodial and cytotoxic activities of medicinal plants traditionally used in the village of Kiohima, Uganda. J Ethnopharmacol 133:850-855

23. Masaba SC (2000) The antimalarial activity of Vernonia amygdalina Del (Compositae). Trans R Soc Trop Med Hyg 94:694-695

24. Omoregie ES, Pal A, Darokar MP, Chanda D, Sisodia B (2010) In vitro and in vivo antiplasmodial activity and cytotoxicity of extracts from Vernonia amygdalina Del. leaves. Malar J 9(Suppl 2):P30

25. Tona L, Ngimbi NP, Tsakala M, Mesia K, Cimanga K, Apers S et al (1999) Antimalarial activity of 20 crude extracts from nine African medicinal plants used in Kinshasa, Congo. J Ethnopharmacol 68:193-203

26. Tona L, Cimanga RK, Mesia K, Musuamba CT, De Bruyne T, Apers S et al (2004) In vitro antiplasmodial activity of extracts and fractions from seven medicinal plants used in the Democratic Republic of Congo. J Ethnopharmacol 93:27-32

27. Abosi AAO, Raseroka BHB (2003) In vivo antimalarial activity of Vernonia amygdalina. Br J Biomed Sci 60:89-91

28. Iwalokun BA (2008) Enhanced antimalarial effects of chloroquine by aqueous Vernonia amygdalina leaf extract in mice infected with chloroquine resistant and sensitive Plasmodium berghei strains. Afr Health $\mathrm{Sci}$ 8:25-35

29. Melariri $P$, Campbell W, Etusim $P$, Smith $P$ (2011) In vitro and in vivo antiplasmodial activities of extracts of Cymbopogon citratus Staph and Vernonia amygdalina Delile leaves. J Nat Prod 4:164-172

30. Njan AA, Adzu B, Agaba AG, Byarugaba D, Díaz-Llera S, Bangsberg DR (2008) The analgesic and antiplasmodial activities and toxicology of Vernonia amygdalina. J Med Food 11:574-581

31. Challand S, Willcox M (2009) A clinical trial of the traditional medicine Vernonia amygdalina in the treatment of uncomplicated malaria. J Altern Complement Med 15:1231-1237

32. Erasto P, Grierson DS, Afolayan AJ (2006) Bioactive sesquiterpene lactones from the leaves of Vernonia amygdalina. J Ethnopharmacol 106:117-120

33. Luo X, Jiang Y, Fronczek F, Lin C, Izevbigie E, Lee K et al (2011) Isolation and structure determination of a sesquiterpene lactone (vernodalinol) from Vernonia amygdalina extracts. Pharm Biol 49:464-470

34. Owoeye O, Yousuf S, Akhtar M, Qamar K, Dar A, Farombi E et al (2010) Another anticancer elemanolide from Vernonia amygdalina Del. Int J Biol Chem Sci 4:226-234

35. Kupchan S, Hemingway R, Karim A, Werner D (1969) Tumor inhibitors. XLVII. Vernodalin and vernomygdin. Two new cytotoxic sesquiterpene lactones from Vernonia amygdalina Del. J Org Chem 34:3908-3911

36. Jisaka M, Ohigashi H, Takagaki T, Nozaki H, Tada T, Hirota M et al (1992) Bitter steroid glucosides, vernoniosides $A 1, A 2$, and $A 3$, and related $B 1$ from a possible medicinal plant, Vernonia amygdalina, used by wild chimpanzees. Tetrahedron 48:625-632

37. Igile GO, Oleszek W, Burda S, Jurzysta M (1994) Flavonoids from Vernonia amygdalina and their antioxidant ativities. J Agric Food Chem 42:2445-2448
38. Laekeman GM, Mertens J, Totté J, Bult H, Vlietinck AJ, Herman AG (1983) Isolation and pharmacological characterization of vernolepin. J Nat Prod 46:161-169

39. Chukwujekwu JC, Lategan CA, Smith PJ, Van Heerden FR, Van Staden J (2009) Antiplasmodial and cytotoxic activity of isolated sesquiterpene lactones from the acetone leaf extract of Vernonia colorata. S Afr J Bot 75:176-179

40. Ohigashi H, Huffman AM, Izutsu D, Koshimizu K, Kawanaka M, Sugiyama $\mathrm{H}$ et al (1994) Toward the chemical ecology of medicinal plant use in chimpanzees: The case of Vernonia amygdalina, a plant used by wild chimpanzees possibly for parasite-related diseases. J Chem Ecol 20:541-553

41. Asaka Y, Kubota T, Kukarni A (1977) Studies on a bitter principle from Vernonia anthelmintica. Phytochemistry 16:1838-1839

42. Rabe T, Mullholland D, van Staden J (2002) Isolation and identification of antibacterial compounds from Vernonia colorata leaves. J Ethnopharmacol 80:91-94

43. Orjuela-Sánchez P, Duggan E, Nolan J, Frangos JA, Carvalho LJM (2012) A lactate dehydrogenase ELISA-based assay for the in vitro determination of Plasmodium berghei sensitivity to anti-malarial drugs. Malar J 11:366

44. Lundie RJ, Koning-Ward TF, Davey GM, Nie CQ, Hansen DS, Lau LS et al (2008) Blood-stage Plasmodium infection induces CD8+ T lymphocytes to parasite-expressed antigens, largely regulated by CD8alpha+ dendritic cells. Proc Natl Acad Sci USA 105:14509-14514

45. Leiden Malaria Research Group (2009) RMgmDB Rodent malaria genetically modified parasites Plasmodium berghei. http://www.pberghei.eu. Accessed 25 Aug 2014

46. Vlachou D, Zimmermann T, Cantera R, Janse CJ, Waters AP, Kafatos FC (2004) Real-time, in vivo analysis of malaria ookinete locomotion and mosquito midgut invasion. Cell Micro 6:671-685

47. Coetzee M, Hunt RH, Wilkerson R, Della TA, Coulibaly MB, Besansky NJ (2013) Anopheles coluzzii and Anopheles amharicus, new members of the Anopheles gambiae complex. Zootaxa 3619:246-274

48. Blagborough AM, Churcher TS, Upton LM, Ghani AC, Gething PW, Sinden RE (1812) Transmission-blocking interventions eliminate malaria from laboratory populations. Nat Commun 2013:4

49. Kiszewski AE (2010) Blocking Plasmodium falciparum malaria transmission with drugs: the gametocytocidal and sporontocidal properties of current and prospective antimalarials. Pharmaceuticals 4:44-68

50. Chotivanich K, Sattabongkot J, Udomsangpetch R, Looareesuwan S, Day NPJ, Coleman RE et al (2006) Transmission-blocking activities of quinine, primaquine, and artesunate. Antimicrob Agents Chemother 50:1927-1930

51. Coleman RE, Nath AK, Schneider I, Song GH, Klein TA, Milhous WK (1994) Prevention of sporogony of Plasmodium falciparum and $P$. berghei in Anopheles stephensi mosquitoes by transmission-blocking antimalarials. Am J Trop Med Hyg 50:646-653

52. Tepongning RN, Lucantoni L, Nasuti CC, Dori GU, Yerbanga SR, Lupidi $\mathrm{G}$ et al (2011) Potential of a Khaya ivorensis-Alstonia boonei extract combination as antimalarial prophylactic remedy. J Ethnopharmacol 137:743-751

53. Jarvis B (2008) Statistical aspects of the microbiological examinations of foods, 2nd edn. Elsevier, Amsterdam, p 8

54. Delves MJ, Ramakrishnan C, Blagborough AM, Leroy D, Wells TNC, Sinden RE (2012) A high-throughput assay for the identification of malarial transmission-blocking drugs and vaccines. Int J Parasitol 42:999-1006

55. Torres JA, Rodriguez MH, Rodriguez MC, Hernandez-Hernandez FC (2005) Plasmodium berghei: effect of protease inhibitors during gametogenesis and early zygote development. Exp Parasitol 111:255-259

56. Delves MJ, Ruecker A, Straschil U, Lelièvre J, Marques S, López-Barragán MJ et al (2013) Male and female Plasmodium falciparum mature gametocytes show different responses to antimalarial drugs. Antimicrob Agents Chemother 57:3268-3274

57. Pradel G (2007) Proteins of the malaria parasite sexual stages: expression function and potential for transmission blocking strategies. Parasitology 134:1911-1929

58. Rupp I, Bosse R, Schirmeister T, Pradel G (2008) Effect of protease inhibitors on exflagellation in Plasmodium falciparum. Mol Bochem Parasitol 158:208-212

59. Rostorfer HH (1949) Comparison of methods for measurement of avian hemoglobin. J Biol Chem 180:901-911 
60. Martínez A, Rajapakse CSK, Naoulou B, Kopkalli Y, Sánchez-delgado RA (2008) The mechanism of antimalarial action of the ruthenium (II)chloroquine complex [RuCl2(CQ)]2. J Biol Inorg Chem 13:703-712

61. Mokoka TA, McGaw LJ, Mdee LK, Bagla VP, Iwalewa EO, Eloff JN (2013) Antimicrobial activity and cytotoxicity of triterpenes isolated from leaves of Maytenusundata (Celastraceae). BMC Complement Altern Med 13:111

62. Bousema T, Dinglasan RR, Morlais I, Gouagna LC, van Warmerdam T, Awono-Ambene PH et al (2012) Mosquito feeding assays to determine the infectiousness of naturally infected Plasmodium falciparum gametocyte carriers. PLoS One 7:e42821

63. Mehra N, Bhasin V (1993) In vitro gametocytocidal activity of artemisinin and its derivatives on Plasmodium falciparum. Jpn J Med Sci Biol 46:37-43

64. Bousema T, Okell L, Shekalaghe S, Griffin JT, Omar S, Sawa P et al (2010) Revisiting the circulation time of Plasmodium falciparum gametocytes: molecular detection methods to estimate the duration of gametocyte carriage and the effect of gametocytocidal drugs. Malar J 9:136

65. Baker DA (2010) Malaria gametocytogenesis. Mol Biochem Parasitol 172:57-65

66. Adebayo OL, James A, Kasim SB, Jagri OP (2014) Leaf extracts of Vernonia amygdalina Del. from Northern Ghana contain bioactive agents that inhibit the growth of some beta-lactamase producing bacteria in vitro. BR. J Pharm Res 4:192-202

67. Imaga NOA, Bamigbetan DO (2013) In vivo biochemical assessment of aqueous extracts of Vernonia amygdalina (Bitter leaf). Int J Nutr Metab 5:22-27

68. Akinjogunla O, Ekoi O, Odeyemi A, Odeyemy A (2011) Phytochemical screening and in vitro antibacterial assessment of aqueous leaf extracts of Vernonia amygdalina (Asteraceae) and Ocimum gratissimum (Lamiaceae) on moxifloxacin resistant Escherichia coli isolated from clinical and environmental samples. Nat Sci 9:42-52

69. Anyasor G, Ogunwenmo K, Ogunnowo A, Alao-Sanni O (2010) Comparative antioxidant phytochemical and proximate analysis of aqueous and methanolic extracts of Vernonia amygdalina and Talinum triangulare.pdf. Pakistan. J Nutr 9:259-264

70. Ghamba P, Balla H, Goje L, Halidu A, Dauda M (2014) In vitro antimicrobial activities of Vernonia amygdalina on selected clinical isolates. Int J Curr Microbiol Appl Sci 3:1103-1113

71. Seidel V (2005) Initial and bulk extraction. In: Sarker SD, Latif Z, Gray Al (eds) Natural products isolation, 2nd edn. Humana press Inc., Totowa, p 36

72. Woods JR, Mo H, Bieberich AA, Alavanja T, Colby DA (2013) Amino-derivatives of the sesquiterpene lactone class of natural products as prodrugs. MedChemComm 4:27-33

73. Jisaka M, Ohigashi H, Takegawa K, Huffman M, Koshimizu K (1993) Antitumoral and antimicrobial activities of bitter sesquiterpene lactone of Vernonia amygdalina, a possible medicinal plant used by wild chimpanzees. Biosci Biotech Biochem 57:833-834
74. Ngbolua KN, Rakotoarimanana H, Rafatro H, Ratsimamanga US, Mudogo V, Mpiana PT et al (2011) Comparative antimalarial and cytotoxic activities of two Vernonia species: Vernonia amygdalina from the Democratic Republic of Congo and Vernonia cinerea subsp vialis endemic to Madagascar. Int J Biol Chem Sci 5:345-353

75. Omorgie E, Pal A, Sisodia B (2011) In vitro antimalarial and cytotoxic activities of leaf extracts of Vernonia amygdalina (Del.). Niger J Basic Appl Sci 19:121-126

76. Bogale M, Petros B (1996) Evaluation of the antimalarial activity of some Ethiopian traditional medicinal plants against Plasmodium falciparum in vitro. SINET Ethiop J 19:233

77. Pedersen MM, Chukwujekwu JC, Lategan CA, van Staden J, Smith PJ, Staerk D (2009) Antimalarial sesquiterpene lactones from Distephanus angulifolius. Phytochemistry 70:601-607

78. Pink R, Hudson A, Mouriès M-A, Bendig M (2005) Opportunities and challenges in antiparasitic drug discovery. Nat Rev Drug Discov 4:727-740

79. Pratheeshkumar P, Kuttan G (2011) Effect of vernolide-A, a sesquiterpene lactone from Vernonia cinerea $\mathrm{L}$., on cell-mediated immune response in B16F-10 metastatic melanoma-bearing mice. Immunopharmacol Immunotoxicol 33:533-538

80. Ibrahim G, Abdurahman M, Ibrahim H, Ibrahim N, Magajii M (2011) Toxicity and analgesic effects of Vernonia amygdalina Del. (Asteraceae) leaf extract on mice. Int J Adv Pharm Biol Sci 1:1-4

81. Luke UO, Robert AE, Egbung GE (2013) Effect of ethanolic root and twig extracts of Vernonia amygdalina (etidot) on liver function parameters of streptozotocin induced hyperglycaemic and normal wistar rats. Eur Sci J 9:199-211

82. Nwanjo HU (2005) Efficacy of aqueous leaf extract of Vernonia amygdalina on plasma lipoprotein and oxidative status in diabetic rat models. Niger J Physiol Sci 20:39-42

83. Yeap S, Liang W, Beh B, Ho W, Yousr A, Alitheen N (2012) In vivo antidiabetic and acute toxicity of spray-dried Vernonia amygdalina water extract. Int Food Res J 20:613-616

84. Sha'a K, Oguche S, Watila I, Ikpa T (2011) In vitro antimalarial activity of the extracts of Vernonia amygdalina commonly used in traditional medicine in Nigeria. Sci World J 6:5-9

85. Akah PA, Alemji JA, Salawu OA, Okoye TC, Offiah NV (2009) Effects of Vernonia amygdalina on biochemical and hematological parameters in diabetic rats. Asian J Med Sci 1:108-113

\section{Submit your next manuscript to BioMed Central and take full advantage of:}

- Convenient online submission

- Thorough peer review

- No space constraints or color figure charges

- Immediate publication on acceptance

- Inclusion in PubMed, CAS, Scopus and Google Scholar

- Research which is freely available for redistribution

Submit your manuscript at

www.biomedcentral.com/submit

C Biomed Central 